\title{
Dynamic Analysis of the High Speed Train and Slab Track Nonlinear Coupling System with the Cross Iteration Algorithm
}

\author{
Xiaoyan Lei, Shenhua Wu, and Bin Zhang \\ Engineering Research Center of Railway Environment Vibration and Noise, Ministry of Education, East China Jiaotong University, \\ Nanchang 330013, China
}

Correspondence should be addressed to Xiaoyan Lei; xiaoyanlei2013@163.com

Received 28 October 2015; Revised 13 January 2016; Accepted 28 January 2016

Academic Editor: Usama El Shamy

Copyright (C) 2016 Xiaoyan Lei et al. This is an open access article distributed under the Creative Commons Attribution License, which permits unrestricted use, distribution, and reproduction in any medium, provided the original work is properly cited.

\begin{abstract}
A model for dynamic analysis of the vehicle-track nonlinear coupling system is established by the finite element method. The whole system is divided into two subsystems: the vehicle subsystem and the track subsystem. Coupling of the two subsystems is achieved by equilibrium conditions for wheel-to-rail nonlinear contact forces and geometrical compatibility conditions. To solve the nonlinear dynamics equations for the vehicle-track coupling system, a cross iteration algorithm and a relaxation technique are presented. Examples of vibration analysis of the vehicle and slab track coupling system induced by China's high speed train CRH3 are given. In the computation, the influences of linear and nonlinear wheel-to-rail contact models and different train speeds are considered. It is found that the cross iteration algorithm and the relaxation technique have the following advantages: simple programming; fast convergence; shorter computation time; and greater accuracy. The analyzed dynamic responses for the vehicle and the track with the wheel-to-rail linear contact model are greater than those with the wheel-to-rail nonlinear contact model, where the increasing range of the displacement and the acceleration is about $10 \%$, and the increasing range of the wheel-to-rail contact force is less than $5 \%$.
\end{abstract}

\section{Introduction}

Since the opening of the world's first high speed railway in 1964 (with its advantages of high speed and convenience, safety and comfort, environmental-friendliness and low energy consumption, larger carrying capacity, and the availability of all-day transportation), high speed railway has shown strong competitiveness amongst other modes of transport. According to the statistics by the International Union of Railways, as of November 1, 2013, there are a total of $11,605 \mathrm{~km}$ of high speed railways in operation, $4883 \mathrm{~km}$ in construction, and another $12,570 \mathrm{~km}$ of high speed railways planned to be built in other countries of the world. In China, there are $11,028 \mathrm{~km}$ of high speed railways in operation and another $12,000 \mathrm{~km}$ under construction, making up half the total amount of the world's total high speed railways, with the country owning the longest and the largest scale of high speed railways both in operation and construction. With the rapid development of high speed railways, ballastless slab track has been widely used throughout the world $[1,2]$. In China, over $80 \%$ high speed railways are ballastless slab track. Compared with the traditional ballast track, it has the advantages of high stability, long service life, high geometric regularity, uniform track stiffness, low maintenance, and good durability.

It is well known that the transportation function of a railway system is achieved by wheel-to-rail interaction, and the design and the manufacture of locomotives and rolling stock, as well as the design and the construction of the line itself, are required for understanding the dynamic characteristics of the vehicle and track coupling system. To ensure the train moves safely and smoothly, a good dynamic performance of the railway line is required. The development of a mathematical model and the simulation technique for analysis of the dynamic behavior of ballastless slab track will be helpful to achieve improved component design and maintenance schedules. These models are used to understand the interactions of the track and vehicle components and to measure the vibration characteristics of the track structure. Some literature has focused on recent developments in slab track and slab track design $[3,4]$. However, only a few references have been made to the dynamic behavior of a ballastless slab track under moving vehicles. Zhai et al. 
developed a vehicle/slab track interaction model based on the theory of vehicle-track coupling dynamics and analyzed the dynamic properties of slab tracks used in high speed railways. The effects of the elasticity and damping of the CA-layer under the slab on system dynamics were also investigated [5]. Xiang et al. established a dynamic analysis model of the lateral finite strip and slab segment element based on the structural characteristics of the ballastless track, such as the Bögl slab track [6]. Both the motor car and trailers of the high speed train were modeled as a multibody system with two suspensions. The vertical displacements of the rail and the slab were obtained by the traditional static model and by the dynamic analysis model of the lateral finite strip and slab segment element, respectively. The calculated results demonstrate that the vertical static and dynamic maximum displacements of the rail and the slab are close and the values are in general range. Next, Xiang et al. put forward a new spatial vibration model of track segment element of the slab track according to structural characteristic of a slab track [7]. The spatial vibration equation set of the high speed train and slab track system was then established on the basis of the rule of "set-in-right-position" for formulating system matrices. The equation set was solved by the Wilson$\theta$ direct integration method. The theory was verified by the high speed running experiment carried out on the slab track of the Qinghuang dao-Shenyang passenger transport line. Dong et al. carried out experimental validation of a numerical model for prediction of the dynamic response of ballastless subgrade of high speed railways [8]. 3D consistent viscous-spring artificial boundary elements are introduced in the ABAQUS software, the effects of the distance between multisource loading points and the viscous-spring artificial boundary on the simulation results under train loading conditions are discussed, and 3D finite element ballastless track/subgrade models have been developed. Comparison between the field measured data of $\mathrm{CRH} 2$ at the National Railway Test Site and the ABAQUS simulation results shows good agreement. The results indicate that the dynamic stress of the subgrade increases with the speed. Lei and Zhang presented a model for dynamic analysis of vehicle-tracksubgrade coupling system to the CRTS II (China Railway Track System) ballastless slab track system [9]. Based on the model, a new type of ballastless slab track element is developed, and the associated stiffness matrix, mass matrix, and damping matrix for the element is deduced. This element includes rail, rail pad and fastener, prefab slab, cementasphalt mortar, hydraulically bonded layer, and subgrade. By means of the Lagrange equation, the finite element equation for analysis of dynamic behavior of the ballastless slab track is formulated. As application examples, parameter studies on the track vibration of the ballastless slab track structure, such as stiffness and damping resulting from the rail pad and fastener, CA mortar, and subgrade, are investigated. In order to investigate the dynamic behavior of the train and slab track coupling system, Lei and Wang studied a new approach with finite elements in a moving frame of reference based on conceptions of vehicle element and track element [10]. By discretizing the slab track subsystem into track elements that flow with the moving vehicle, the proposed method eliminates the need for keeping track of the vehicle position with respect to the track model. The governing equations are formulated in a coordinate system moving at a constant velocity, and the associated stiffness matrix, mass matrix, and damping matrix for the track element in a moving frame of reference are derived. The vehicle element is introduced to model a car with primary and secondary suspension systems, which has 26 degrees of freedom, where 10 degrees of freedom are used to describe the vertical movement of the car, and 16 degrees of freedom are associated with rail displacements. The method is shown to work for varying train speed and track parameters and has several advantages over the conventional finite element method in a fixed system of reference. (It is known that track irregularity is the principal exciting source inducing vibrations of the train and the track.) Kang et al. proposed a calculation method, fitting function and fitting spectrum of power spectral density (PSD) of track irregularity for high speed railways [11]. To improve the calculation accuracy of PSD of track irregularity, a linear interpolation and a wavelet analysis are given and used to eliminate the outliers and trends in the track irregularities. Based on the method and the data from the high speed comprehensive inspection train, the track irregularity PSD fitting equation was obtained, as well as the frequency multiplication energy table, to reflect the impact of track periodical structure of high speed railways. PSD of the ballastless track irregularities of high speed railway includes fitting spectrum and frequency multiplication energy table, which provides the basis for maintenance and optimization design for high speed railways. By means of a parallel algorithm based on the pseudo excitation method (PEM), Zhang et al. investigated the nonstationary random response of a vertically coupled vehicle-slab track system subjected to random excitation induced by track irregularity [12]. The vehicle is simplified as a multibody system with 10 degrees of freedom and the slab track is represented by a three-layer Bernoulli-Euler beam model which includes the rail, slab, and roadbed. Linear wheel-rail contact provides interaction between the vehicle and slab track models. In the above contributions, studies are mainly focused on the vehicletrack linear coupling dynamic problems and have their own characteristics, whereas the analysis of dynamic response for the vehicle-track nonlinear coupling system is rarely given attention, as is the corresponding algorithm. Varandas et al. presented a methodology to predict the settlement of railway track in transition zones due to train loading [13]. The methodology is based on dynamic calculations using a (non-linear) train-track interaction model and an incremental settlement model. Nguyen et al. carried out comparison of dynamic effects of high speed traffic load on ballasted track using a simplified two-dimensional and full three-dimensional model [14]. In these models, the vehicle and track are coupled via a nonlinear Hertz contact mechanism. The method of Lagrange multipliers is used for the contact constraint enforcement between the wheel and rail. Due to the contact nonlinearities, the numerical simulations are performed in the time domain, using a direct integration method for the transient problem. Yang and Fonder presented an iterative scheme to analyze the dynamic 
response of a bridge-vehicle system [15]. The method consists in dividing the whole system into two subsystems at the interface of the bridge and vehicles, and these two subsystems are solved separately. Their compatibility at the interface is achieved by an iterative procedure with underrelaxation or with Aitken acceleration. The proposed method is more efficient in nonlinear dynamic responses because, in this case, the iterations are necessary whether the system is solved as a whole or not. In each iteration step, judgment must be made to satisfy equilibrium conditions for wheelrail nonlinear contact forces and geometrical compatibility conditions, and the select of the time step will be limited when dealing with problem of the larger amplitude of the track random irregularity. A fundamental model is established for analyzing the train-track-bridge dynamic interactions by Zhai and Xia, in which the vehicle subsystem is coupled with the track subsystem through a spatially interacted wheelrail model [16, 17]; and the track subsystem is coupled with the bridge subsystem by a track-bridge dynamic interaction model. An explicit-implicit integration scheme is adopted to numerically solve the equations of motion of the large nonlinear dynamic system in the time domain. Computer simulation software, that is, the train-track-bridge interaction simulation software (TTBSIM), is developed to predict the vertical and lateral dynamic responses of the train-trackbridge coupled system, and the effectiveness of the TTBSIM simulation for dynamic evaluation of complex bridge structures in high speed railways is demonstrated [16, 17]. Neves et al. pointed out that the equations of motion of the structure and vehicles are complemented with additional compatibility equations that relate nodal displacements of the vehicles to the displacements of the corresponding points on the surface of the structure, with no sliding or separation $[18,19]$. In order to avoid the system matrix being time dependent at each time step and deal with the nonlinear contact problem, a model for dynamic analysis of the vehicle and slab track nonlinear coupling system is proposed by finite element method in this paper. The whole system is divided into two subsystems: the vehicle subsystem (considered as a complete locomotive or rolling stock unit with a primary and secondary suspension system) and the track subsystem (regarded as three-layer elastic beam model). Coupling of the two systems is achieved by equilibrium conditions for wheelto-rail nonlinear contact forces and geometrical compatibility conditions. A cross iteration algorithm is presented to solve the dynamics equations of the vehicle-track nonlinear coupling system. In order to accelerate the iteration convergence rate, a relaxation technique is introduced to modify the wheel-to-rail contact forces. By contrasting with a reference example, the correctness of the algorithm is verified. The example of vehicle and track vibration induced by China high speed train CRH3 moving on the slab track is given, in which the influences of the linear and nonlinear wheel-to-rail contact model and the different train speeds are considered. The results demonstrate that the cross iteration algorithm has the advantages of simple programming, fast convergence rate, less computation time and high accuracy.

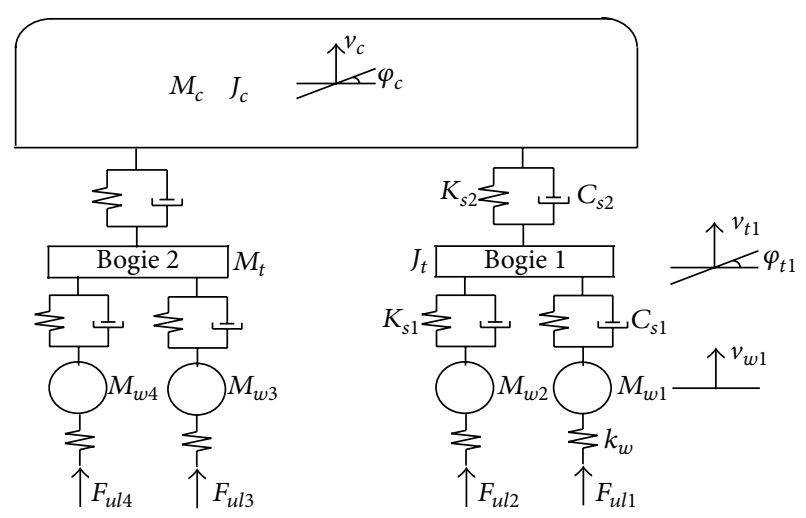

Figure 1: Vehicle model as upper subsystem.

\section{Fundamental Assumptions}

The following assumptions are made in establishing the model to analyze the dynamic behavior of the ballastless slab track of high speed railways:

(1) Only vertical dynamic loads are considered in the model.

(2) Since the vehicle and the slab track are symmetrical about the center-line of the track, only half of the coupling system is used for ease of calculation.

(3) The upper structure in the vehicle and slab track coupling system is a complete locomotive or rolling stock unit with a primary and secondary suspension system, in which vertical and pitch motion for both vehicle and bogie are considered.

(4) The lower structure in the coupling system is a CRTS II slab track where rails are considered as beams with finite length resting on a discrete pad. The elastic and damping behavior for the rail pad and the fastener of the track structure are represented with stiffness and damping coefficients $k_{y 1}$ and $c_{y 1}$.

(5) The concrete slab is simplified as a beam, and only vertical dynamic responses are considered. The elastic and damping behavior resulting from cement-asphalt mortar (CA mortar) of the track structure are $k_{y_{2}}$ and $c_{y 2}$.

(6) The hydraulically bonded layer (HBL) is simplified as a beam, and only vertical dynamic responses are considered. The elastic and damping behavior resulting from subgrade of the track structure are $k_{y 3}$ and $c_{y 3}$.

(7) A nonlinear relationship between two elastic contact cylinders perpendicular to each other is used in coupling the vehicle and the track.

\section{Vehicle Subsystem}

The vehicle subsystem is a complete locomotive or rolling stock unit with a primary and secondary suspension system, as shown in Figure 1 . In the model, $2 M_{c}$ and $2 J_{c}$ are mass 
and pitch inertia for the car body; $2 M_{t}$ and $2 J_{t}$ are mass and pitch inertia for the bogie; $k_{s 1}, k_{s 2}$ and $c_{s 1}, c_{s 2}$ stand for stiffness and damping coefficients for the primary and secondary suspension systems of the vehicle, respectively; $v_{c}$ and $\varphi_{c}$ are vertical displacement and angular displacement of pitch motion for the car body; $v_{t i}(i=1,2)$ and $\varphi_{t i}(i=1,2)$ are the vertical displacement and angular displacement of pitch motion for the $i$ th bogie; $v_{w i}(i=1,2,3,4)$ is the vertical displacement for the $i$ th wheel; $M_{w i}(i=1,2,3,4)$ is the mass of the $i$ th wheel and $F_{u l i}(i=1,2,3,4)$ is the wheel-to-rail contact force for the $i$ th wheel. The nodal displacement vector for this element can be defined as

$$
\underline{a}_{u}=\left\{\begin{array}{llllllllll}
v_{c} & \varphi_{c} & v_{t 1} & v_{t 2} & \varphi_{t 1} & \varphi_{t 2} & v_{w 1} & v_{w 2} & v_{w 3} & v_{w 4}
\end{array}\right\}^{T} .
$$

By means of the Lagrange equation, the dynamic equation of vehicle for the coupling system can be obtained as

$$
\underline{M}_{u} \underline{\ddot{a}}_{u}+\underline{C}_{u} \underline{\dot{a}}_{u}+\underline{K}_{u} \underline{a}_{u}=\underline{Q}_{u},
$$

where $\underline{M}_{u}, \underline{C}_{u}$, and $\underline{K}_{u}$ represent the mass, damping, and stiffness matrixes for the upper structure and the explicit expressions can be described as

$$
\begin{aligned}
& \underline{M}_{u} \\
& =\operatorname{diag}\left(\begin{array}{lllllllllll}
M_{c} & J_{c} & M_{t} & M_{t} & J_{t} & J_{t} & M_{w 1} & M_{w 2} & M_{w 3} & M_{w 4}
\end{array}\right) .
\end{aligned}
$$

$\underline{C}_{u}$ and $\underline{K}_{u}$ can be found in the literature [9].

$\underline{Q}_{u}$ is the load vector for the upper structure

$$
\begin{aligned}
& \{Q\}_{u} \\
& \quad=\left\{\begin{array}{llllllllll}
-M_{c} g & 0 & -M_{t} g & -M_{t} g & 0 & 0 & P_{1} & P_{2} & P_{3} & P_{4}
\end{array}\right\}^{T} .
\end{aligned}
$$

$P_{i}=-M_{w i} g+F_{u l i}$ and $F_{u l i}$ stands for the wheel-to-rail contact force for the $i$ th wheel, which can be calculated by the nonlinear Hertz formula

$$
\begin{aligned}
& F_{u l i} \\
& \quad= \begin{cases}\frac{1}{G^{3 / 2}}\left|v_{w i}-\left(v_{l c i}+\eta_{i}\right)\right|^{3 / 2} & v_{w i}-\left(v_{l c i}+\eta_{i}\right)<0 \\
0 & v_{w i}-\left(v_{l c i}+\eta_{i}\right) \geq 0,\end{cases}
\end{aligned}
$$

where $v_{w i}$ and $v_{l c i}$ are the vertical displacement for the $i$ th wheel and the $i$ th rail on the $i$ th wheel/rail contact point, respectively, $\eta_{i}$ stands for irregularity of the track vertical profile at the rail contact point with $i$ th wheel, and $G$ is the deflection coefficient of the contact between the wheel and the rail, which can be referenced in the literature [20].

\section{CRTS II Slab Track Subsystem}

A slab track element model with three layer beams is developed in Figure 2 and the whole slab track subsystem model is described in Figure 3. In the model, $v_{1}, v_{4}$ and $\theta_{1}, \theta_{4}$ are vertical rail displacements and rail slopes for node 1 and node $4 ; v_{2}, v_{5}$ and $\theta_{2}, \theta_{5}$ are vertical displacements and slopes of the concrete slab for node 2 and node 5; and $v_{3}, v_{6}$ and $\theta_{3}$,

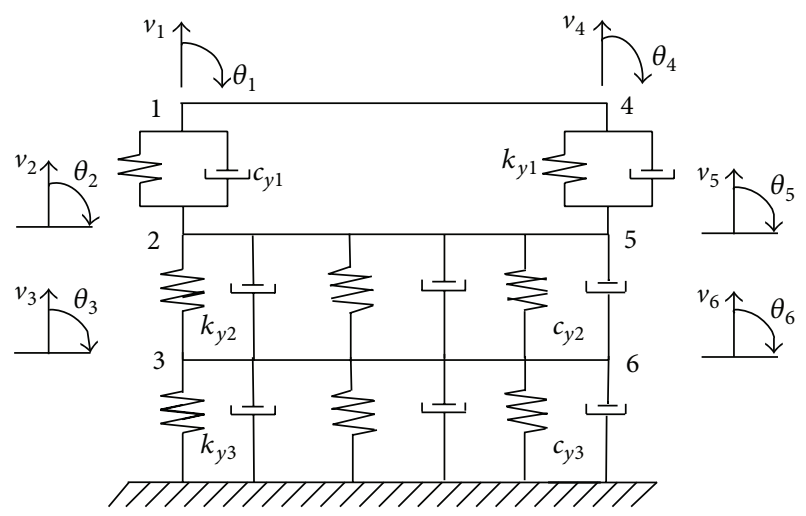

Figure 2: Slab track element model.

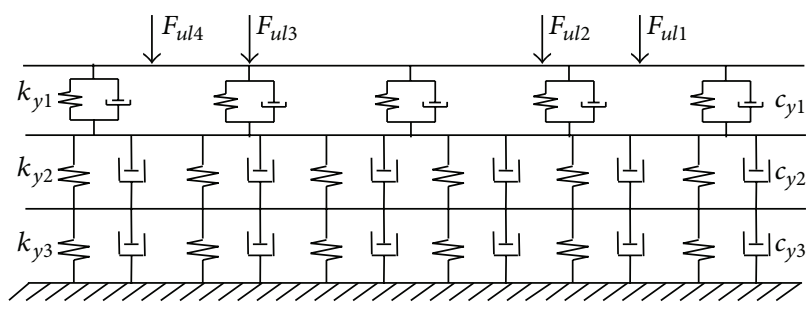

Figure 3: Ballastless slab track model as lower subsystem.

$\theta_{6}$ are vertical displacements and slopes of the hydraulically bonded layer for node 3 and node 6 .

The nodal displacement vector for the slab track element can be defined as

$$
\underline{a}_{l}^{e}=\left\{\begin{array}{llllllllllll}
v_{1} & \theta_{1} & v_{2} & \theta_{2} & v_{3} & \theta_{3} & v_{4} & \theta_{4} & v_{5} & \theta_{5} & v_{6} & \theta_{6}
\end{array}\right\}^{T} .
$$

Using finite element method, the dynamic equation of slab track in the coupling system can be described as

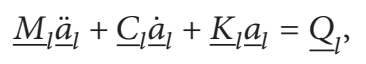

where $\underline{M}_{l}, \underline{C}_{l}$, and $\underline{K}_{l}$ stand for global mass matrix, global damping matrix, and global stiffness matrix of the ballastless slab track subsystem, respectively, and the explicit expressions can be described as

$$
\begin{aligned}
\underline{M}_{l} & =\sum_{e} \underline{m}_{l}^{e}, \\
\underline{C}_{l} & =\sum_{e} \underline{c}_{l}^{e}, \\
\underline{K}_{l} & =\sum_{e} \underline{k}_{l}^{e},
\end{aligned}
$$

where $\underline{m}_{l}^{e}, c_{l}^{e}$, and $\underline{k}_{l}^{e}$ are the mass matrix, damping matrix, and stiffness matrix of the slab track element, respectively, and the expressions can be represented as

$$
\begin{aligned}
\underline{m}_{l}^{e} & =\underline{m}_{r}^{e}+\underline{m}_{s}^{e}+\underline{m}_{h}^{e}, \\
\underline{k}_{l}^{e} & =\underline{k}_{r}^{e}+\underline{k}_{s}^{e}+\underline{k}_{h}^{e}+\underline{k}_{1 c}^{e}+\underline{k}_{2 c}^{e}+\underline{k}_{3 c}^{e}, \\
\underline{c}_{l}^{e} & =\underline{c}_{r}^{e}+\underline{c}_{1 c}^{e}+\underline{c}_{2 c}^{e}+\underline{c}_{3 c}^{e},
\end{aligned}
$$


where $\underline{m}_{r}^{e}, \underline{m}_{s}^{e}$, and $\underline{m}_{h}^{e}$ are mass matrixes associated with the rail, the concrete slab, and the hydraulically bonded layer; $\underline{k}_{r}^{e}$, $k_{s}^{e}$, and $k_{h}^{e}$ are modified versions of stiffness matrixes for the standard beam elements due to strain energies of the rail, the concrete slab, and the hydraulically bonded layer; $\underline{k}_{1 c}^{e}, \underline{k}_{2 c}^{e}$, and $\underline{k}_{3 c}^{e}$ are stiffness matrixes resulting from elastic elements of the rail pad and fastener, the cement-asphalt mortar, and the subgrade; $\underline{c}_{r}^{e}$ is a damping matrix for the rail, the concrete slab, and the hydraulically bonded layer; $\underline{c}_{1 c}^{e}, \underline{c}_{2 c}^{e}$, and $\underline{c}_{3 c}^{e}$ are damping matrixes resulting from damping elements of the rail pad and fastener, the cement-asphalt mortar, and the subgrade. All the expressions can be found in the literature [9].

\section{Cross Iteration Algorithm}

In order to solve the dynamic equations of the vehicle-track nonlinear coupling system, the Newmark integration method is used and the detailed procedure of cross iteration algorithm is given as follows. For the vehicle subsystem, (2) can be rewritten as

$$
\underline{M}_{u} \underline{\ddot{a}}_{u}+\underline{C}_{u} \underline{\dot{a}}_{u}+\underline{K}_{u} \underline{a}_{u}=\underline{Q}_{u g}+\underline{F}_{u l}
$$

where $\underline{Q}_{u g}$ is the gravity vector for the vehicle and $\underline{F}_{u l}$ is the vector of wheel-to-rail contact force, which can be calculated by nonlinear Hertz formula (5).

Taking the Hertz nonlinear stiffness into linearization, formula (5) can be rewritten as

$$
\underline{F}_{u l}= \begin{cases}-\underline{K}_{w}\left(\underline{a}_{u}-\underline{a}_{l c}-\underline{\eta}\right) & \left(\underline{a}_{u}-\underline{a}_{l c}-\underline{\eta}\right)_{i}<0 \\ 0 & \left(\underline{a}_{u}-\underline{a}_{l c}-\underline{\eta}\right)_{i} \geq 0\end{cases}
$$

where $\underline{K}_{w}$ is the linearized stiffness matrix of wheel-to-rail contact, $\eta$ is the vector of track irregularity at the wheel-torail contact points

$$
\begin{aligned}
& \underline{Q}_{u g} \\
& =-g\left\{\begin{array}{llllllllll}
M_{c} & 0 & M_{t} & M_{t} & 0 & 0 & M_{w 1} & M_{w 2} & M_{w 3} & M_{w 4}
\end{array}\right\}^{T}, \\
& \underline{a}_{u}=\left\{\begin{array}{lllllllllll}
v_{c} & \varphi_{c} & v_{t 1} & v_{t 2} & \varphi_{t 1} & \varphi_{t 2} & v_{w 1} & v_{w 2} & v_{w 3} & v_{w 4}
\end{array}\right\}^{T},
\end{aligned}
$$

$$
\begin{aligned}
\underline{a}_{l c} & =\left\{\begin{array}{llllllllll}
0 & 0 & 0 & 0 & 0 & 0 & v_{l c 1} & v_{l c 2} & v_{l c 3} & v_{l c 4}
\end{array}\right\}^{T}, \\
\underline{K}_{w} & =\operatorname{diag}\left\{\begin{array}{llllllllll}
0 & 0 & 0 & 0 & 0 & 0 & k_{w} & k_{w} & k_{w} & k_{w}
\end{array}\right\}, \\
k_{w} & =\frac{3}{2 G} p_{0}{ }^{1 / 3}(\mathrm{~N} / \mathrm{cm}),
\end{aligned}
$$

where $k_{w}$ is the linearized contact stiffness between the wheel and the rail and $p_{0}$ is the static load of the wheel.

Substituting (11) into (10), (10) can be expressed as

$$
\underline{M}_{u} \underline{\ddot{a}}_{u}+\underline{C}_{u} \underline{\dot{a}}_{u}+\left(\underline{K}_{u}+\underline{K}_{w}\right) \underline{a}_{u}=\underline{Q}_{u g}+\underline{K}_{w}\left(\underline{a}_{l c}+\underline{\eta}\right) .
$$

For the subsystem of the slab track, (7) can be rewritten as

$$
\underline{M}_{l} \underline{\underline{a}}_{l}+\underline{C}_{l} \underline{\dot{a}}_{l}+\underline{K}_{l} \underline{a}_{l}=\underline{Q}_{\mathrm{gg}}-\underline{F}_{u l},
$$

where $\underline{Q}_{\lg }$ is the nodal load vector induced by gravity of the track structure and $\underline{F}_{u l}$ is the wheel-to-rail force vector.

The Newmark integration method is used to solve the dynamic responses of the vehicle subsystem and the track subsystem, which is widely used in engineering practice. Parameters and procedures of the Newmark method can be found in the literature [21]. follows.

The fundamental computation steps are summarized as

Stage 1 (initial computation). (1) In the first time step and first iteration, assume the initial displacement $\underline{a}_{l}^{0}$ of the track structure (usually taking $\underline{a}_{l}^{0}=0$ ). Based on the value of $\underline{a}_{l}^{0}$, the initial displacement of the rail $v_{l c i}^{0}(i=$ $1,2,3,4)$ can be derived at the $i$ th wheel-to-rail contact point. Next, substituting $v_{l c i}^{0}(i=1,2,3,4)$ into (14), the initial displacement vector $\underline{a}_{l c}^{0}$ can be obtained.

(2) Substituting $\underline{a}_{l c}^{0}$ into (17), the displacement $\underline{a}_{u}^{0}$, velocity $\underline{\dot{a}}_{u}^{0}$, and acceleration $\underline{\ddot{a}}_{u}^{0}$ of the vehicle can be evaluated by solving for the motion of vehicle equation (17).

Stage 2 (step by step procedure in time domain). Assume that in time step $(t)$ the $(k-1)$ th iteration has been done and vectors of the displacement, velocity, and acceleration at time step $(t)$ for the vehicle and the track structure are known. Now let us consider the $(k)$ th iteration.

(1) By substituting ${ }^{t} \underline{a}_{u}^{k-1}$ and ${ }^{t} \underline{a}_{l c}^{k-1}$ into (5), calculate the interaction force ${ }^{t} F_{u l i}^{k}(i=1,2,3,4)$ by flowing formula

$$
{ }^{t} F_{u l i}^{k}= \begin{cases}\frac{1}{G^{3 / 2}}\left|{ }^{t} v_{w i}^{k-1}-\left({ }^{t} v_{l c i}^{k-1}+{ }^{t} \eta_{i}^{k-1}\right)\right|^{3 / 2} & { }^{t} v_{w i}^{k-1}-\left({ }^{t} v_{l c i}^{k-1}+{ }^{t} \eta_{i}^{k-1}\right)<0 \\ 0 & { }^{t} v_{w i}^{k-1}-\left({ }^{t} v_{l c i}^{k-1}+{ }^{t} \eta_{i}^{k-1}\right) \geq 0 .\end{cases}
$$

(2) The relaxation method is introduced to modify the wheelto-rail contact force ${ }^{t} F_{u l i}^{k}(i=1,2,3,4)$; that is,

$$
{ }^{t} F_{u l i}^{k}={ }^{t} F_{u l i}^{k-1}+\mu\left({ }^{t} F_{u l i}^{k}-{ }^{t} F_{u l i}^{k-1}\right),
$$

where $\mu$ is relaxation coefficient which has to be in a certain range $(0<\mu<1)$ to ensure the convergence. If $\mu=1$, it is difficult to converge, especially in case of dealing with problem by consideration of the track random irregularity with larger amplitude. It shows that it is optimal when the 
TABLE 1: Parameters for China high speed train CRH3.

\begin{tabular}{|c|c|c|c|}
\hline Parameters & Value & Parameters & Value \\
\hline Mass of car body $2 M_{c}(\mathrm{~kg})$ & 40000 & $\begin{array}{l}\text { Damping of primary suspension system } \\
2 c_{s 1}(\mathrm{KN} \cdot \mathrm{s} / \mathrm{m})\end{array}$ & 100 \\
\hline Mass of bogie $2 M_{t}(\mathrm{~kg})$ & 3200 & $\begin{array}{l}\text { Damping of secondary suspension system } \\
2 c_{s 2}(\mathrm{kN} \cdot \mathrm{s} / \mathrm{m})\end{array}$ & 120 \\
\hline Mass of wheel $M_{w i}(\mathrm{~kg})$ & 1200 & Wheelbase $2 l_{1}(\mathrm{~m})$ & 2.50 \\
\hline Pitch inertia of car body $2 J_{c}\left(\mathrm{~kg} \cdot \mathrm{m}^{2}\right)$ & $5.47 \times 10^{5}$ & $\begin{array}{l}\text { Distance between center of front bogie } \\
\text { and center of rear bogie } 2 l_{2}(\mathrm{~m})\end{array}$ & 17.375 \\
\hline Pitch inertia of bogie $2 J_{t}\left(\mathrm{~kg} \cdot \mathrm{m}^{2}\right)$ & 6800 & Stiffness of wheel/rail contact $k_{c}(\mathrm{MN} / \mathrm{m})$ & $1.325 \times 10^{3}$ \\
\hline $\begin{array}{l}\text { Stiffness of primary suspension system } 2 k_{s 1} \\
(\mathrm{MN} / \mathrm{m})\end{array}$ & 2.08 & Axle load $(\mathrm{kN})$ & 140 \\
\hline $\begin{array}{l}\text { Stiffness of secondary suspension system } 2 k_{s 2} \\
(\mathrm{MN} / \mathrm{m})\end{array}$ & 0.8 & Length of vehicle (m) & 25.675 \\
\hline
\end{tabular}

relaxation coefficient meets $0.3<\mu<0.5$ and sufficient accuracy can be obtained with less computation time.

(3) Assembling ${ }^{t} F_{u l i}^{k}$ into the wheel-to-rail force vector ${ }^{t} \underline{F}_{u l}^{k}$, which is applied to the lower part of the track structure, as shown in Figure 3 , the displacement ${ }^{t} \underline{a}_{l}{ }^{k}$, velocity ${ }^{t} \underline{\underline{a}}_{l}^{k}$, and acceleration ${ }^{t} \underline{a}_{l}^{k}$ for the track structure can be evaluated by solving (18).

(4) Based on ${ }^{t} \underline{a}_{l}^{k}$, the displacement ${ }^{t} v_{l c i}^{k}(i=1,2,3,4)$ of the rail can be obtained at the $i$ th wheel-to-rail contact point, and the updated wheel-to-rail force ${ }^{t} F_{u l i}^{k}$ acting on the vehicle can be calculated with formula (5).

(5) Assembling the updated ${ }^{t} F_{u l i}^{k}$ into the wheel-to-rail force vector ${ }^{t} \underline{F}_{u l}^{k}$, which is applied to the upper structure as external forces, the displacement ${ }^{t} \underline{a}_{u}^{k}$, velocity ${ }^{t} \underline{\dot{a}}_{u}^{k}$, and acceleration ${ }^{t} \underline{a}_{u}^{k}$ for the vehicle subsystem can be evaluated by solving (10).

(6) Calculate track displacement difference and its norm:

$$
\left\{\Delta^{t} \underline{a}_{l}^{k}={ }^{t} \underline{a}_{l}^{k}-{ }^{t} \underline{a}_{l}^{k-1},\right.
$$

where ${ }^{t} \underline{a}_{l}^{k}$ and ${ }^{t} \underline{a}_{l}^{k-1}$ are displacement vectors of the lower structure at current iteration and previous iteration, respectively.

Now, define the convergence criterion

$$
\frac{\operatorname{Norm}\left\{\Delta^{t} \underline{a}_{l}^{k}\right.}{\operatorname{Norm}\left({ }^{t} \underline{a}_{l}^{k}\right)} \leq \varepsilon,
$$

where

$$
\begin{aligned}
& \operatorname{Norm}\left\{\Delta^{t} \underline{a}_{l}\right\}_{l}^{k}=\sum_{i=1}^{n}\left\{\Delta^{t} \underline{a}^{2}(i)\right\}_{l}^{k}, \\
& \operatorname{Norm}\left({ }^{t} \underline{a}_{l}^{k}\right)=\sum_{i=1}^{n}\left\{{ }^{t} \underline{a}_{l}^{k}(i)\right\}^{2}
\end{aligned}
$$

and $\varepsilon$ is a specified tolerance and assumed between $1.0 \times 10^{-5}$ and $1.0 \times 10^{-8}$, usually sufficient to obtain the solution with reasonable accuracy.
(7) Check convergence criterion (22).

If convergence criterion (22) is not satisfied, go to Stage 2 and enter the next iteration step $(k+1)$. If it is satisfied, proceed to the next instant $(t+\Delta t)$ and define

$$
\begin{aligned}
& { }^{t+\Delta t} \underline{a}_{u}{ }^{0}={ }^{t} \underline{a}_{u}^{k}, \\
& { }^{t+\Delta t} \underline{\dot{a}}_{u}^{0}={ }^{t} \underline{\dot{a}}_{u}^{k}, \\
& { }^{t+\Delta t} \ddot{a}_{u}^{0}={ }^{t} \underline{a}_{u}^{k}, \\
& { }^{t+\Delta t} \underline{a}_{l}^{0}={ }^{t} \underline{a}_{l}^{k}, \\
& { }^{t+\Delta t} \underline{\dot{a}}_{l}{ }^{0}={ }^{t} \underline{\dot{a}}_{l}^{k}, \\
& { }^{t+\Delta t} \underline{\ddot{a}}_{l}^{0}={ }^{t} \underline{\underline{a}}_{l}^{k} .
\end{aligned}
$$

Hence return to Stage 2, enter the next Newmark time step, and continue the calculation until the last time step.

\section{Verification}

In order to verify the correctness of the cross iteration algorithm for the model and the method proposed in this paper to calculate the example in literature [6], analysis of dynamic response for vehicle and track is carried out, where China's high speed train CRH3 with the speed of $200 \mathrm{~km} / \mathrm{h}$ and the CRTS II ballastless slab track are considered. Parameters of the high speed train CRH3 and the CRTS II slab track are given in Tables 1 and 2, respectively. As excitation source of the track profile irregularity, periodic sine function with amplitude $3 \mathrm{~mm}$ and wave length $12.5 \mathrm{~m}$ is adopted in the computation. The calculated vertical rail displacements and the wheel-rail contact forces derived from the two different computational methods are shown and compared in Figures 4 and 5, respectively. Good agreements between the two calculations are observed, which confirms the validity and practicability of the algorithm.

Figures 6 and 7 show the iteration convergence process of the wheel-rail contact force and the rail displacement of the wheel-rail contact point at the time $t$. It can be observed that 
TABLE 2: Parameters for CRTS II slab track.

\begin{tabular}{|c|c|c|}
\hline & Parameters & Value \\
\hline \multirow{3}{*}{ Rail pad } & Distance of ties $l(\mathrm{~m})$ & 0.625 \\
\hline & Stiffness of clips and pad $k_{y 1}\left(\mathrm{MN} \cdot \mathrm{m}^{-1}\right)$ & 60 \\
\hline & Damping of clips and pad $c_{y 1}\left(\mathrm{kN} \cdot \mathrm{s} \cdot \mathrm{m}^{-1}\right)$ & 50 \\
\hline \multirow{5}{*}{ Concrete slab } & Length $(\mathrm{m})$ & 6.45 \\
\hline & Width (m) & 2.55 \\
\hline & Height $(\mathrm{m})$ & 0.20 \\
\hline & Density $\rho_{s}\left(\mathrm{~kg} \cdot \mathrm{m}^{-3}\right)$ & 2500 \\
\hline & Young's modulus $E_{s}(\mathrm{MPa})$ & $3.9 \times 10^{4}$ \\
\hline \multirow{2}{*}{ Cement-asphalt mortar } & Stiffness $k_{y 2}\left(\mathrm{MN} \cdot \mathrm{m}^{-1}\right)$ & $0.9 \times 10^{3}$ \\
\hline & Damping $c_{y 2}\left(\mathrm{kN} \cdot \mathrm{s} \cdot \mathrm{m}^{-1}\right)$ & 80 \\
\hline \multirow{5}{*}{ Hydraulically bonded layer } & Upper bottom width (m) & 2.95 \\
\hline & Lower bottom width (m) & 3.25 \\
\hline & Height (m) & 0.30 \\
\hline & Density $\rho_{h}\left(\mathrm{~kg} \cdot \mathrm{m}^{-3}\right)$ & 2500 \\
\hline & Damping $E_{h}(\mathrm{MPa})$ & $3.3 \times 10^{4}$ \\
\hline \multirow{2}{*}{ Subgrade } & Stiffness $k_{y 3}\left(\mathrm{MN} \cdot \mathrm{m}^{-1}\right)$ & 65 \\
\hline & Damping $c_{y_{3}}\left(\mathrm{kN} \cdot \mathrm{s} \cdot \mathrm{m}^{-1}\right)$ & 90 \\
\hline
\end{tabular}

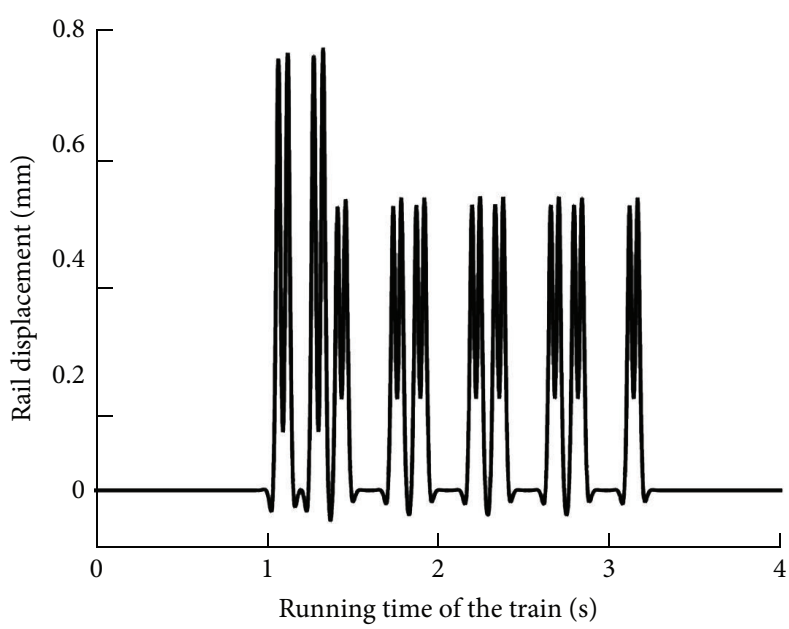

(a) The results in this paper

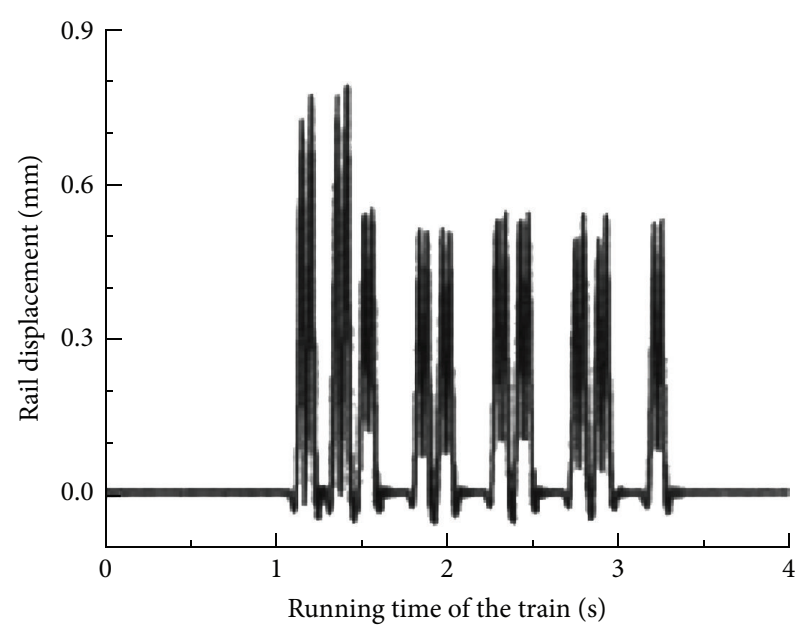

(b) The results in the literature [6]

FIGURE 4: Time history of the vertical rail displacements.

starting from the previous equilibrium state at the time ( $t-$ $\Delta t$ ) the solution quickly approaches convergence after several iterations.

\section{Dynamic Analysis of the High Speed Train and Slab Track Nonlinear Coupling System}

As an application example, dynamic analysis of the vehicle and track nonlinear coupling system induced by China high speed train CRH3 moving on the ballastless slab track is carried out. Parameters for high speed train $\mathrm{CRH} 3$ and the ballastless slab track are given in Tables 1 and 2, respectively. In order to reduce the boundary effect of the track structure, the total track length for computation is $370 \mathrm{~m}$. Random irregularity of the track vertical profile with line grade 6 PSD of the United State is regarded as the external excitation. Influences of the linear and nonlinear wheel-to-rail contact models and different train speeds $(V=200 \mathrm{~km} / \mathrm{h}, 250 \mathrm{~km} / \mathrm{h}$, $300 \mathrm{~km} / \mathrm{h}$, and $350 \mathrm{~km} / \mathrm{h}$ ) on the dynamic responses of the train and the track are investigated. The time step of numerical integration for the Newmark scheme adopts $0.0005 \mathrm{~s}$.

The results computed by varying train speeds, and consideration of linear and nonlinear wheel-to-rail contact model upon the dynamic response of the track and the train, have been given in Tables 3-15 and shown in Figures 8 and 9, where the outputs are the maximum and total amplitude of displacements and accelerations for the rail, the concrete slab, the hydraulically bonded layer, the wheel, the car body and the bogie, and the maximum wheel-rail contact forces. 
TABLE 3: The maximum and the total amplitude of the rail displacements.

\begin{tabular}{lcccccc}
\hline \multirow{2}{*}{ Speed $(\mathrm{km} / \mathrm{h})$} & \multicolumn{2}{c}{ Wheel-to-rail linear contact } & \multicolumn{3}{c}{ Wheel-to-rail nonlinear contact } \\
& Max $(\mathrm{mm})$ & Min $(\mathrm{mm})$ & Total amplitude $(\mathrm{mm})$ & Max $(\mathrm{mm})$ & Min $(\mathrm{mm})$ & Total amplitude $(\mathrm{mm})$ \\
\hline 350 & 0.28 & -1.90 & 2.18 & 0.28 & -1.70 & 1.98 \\
300 & 0.22 & -1.70 & 1.92 & 0.28 & -1.60 & 1.88 \\
250 & 0.20 & -1.60 & 1.80 & 0.19 & -1.60 & 1.79 \\
200 & 0.15 & -1.40 & 1.55 & 0.16 & -1.30 & 1.46 \\
\hline
\end{tabular}

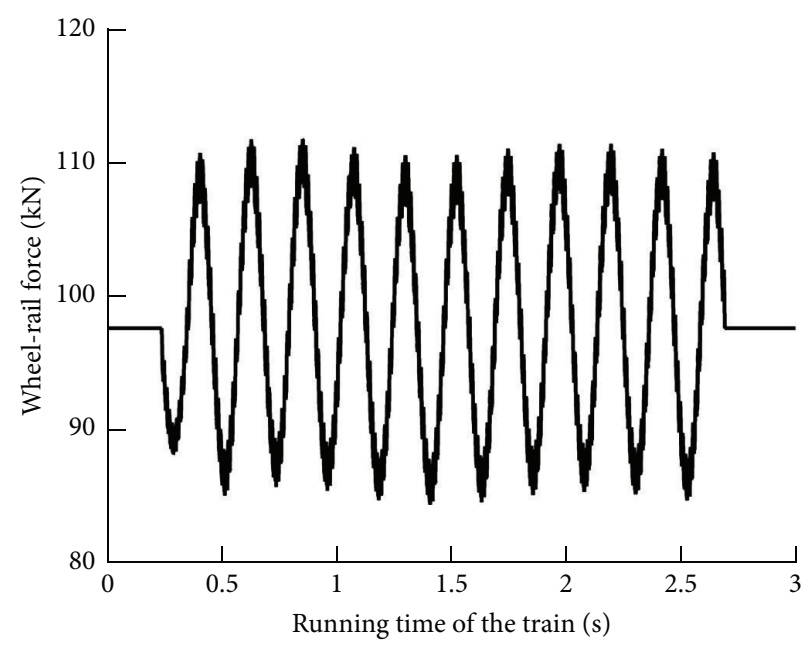

(a) The results in this paper

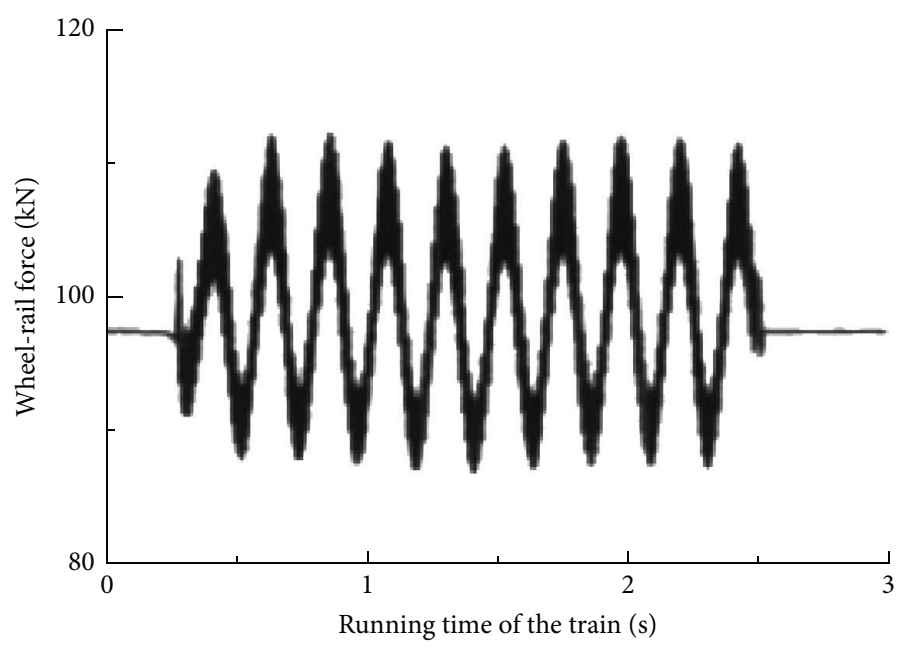

(b) The results in the literature [6]

FIgURE 5: Time history of the wheel-rail contact force.

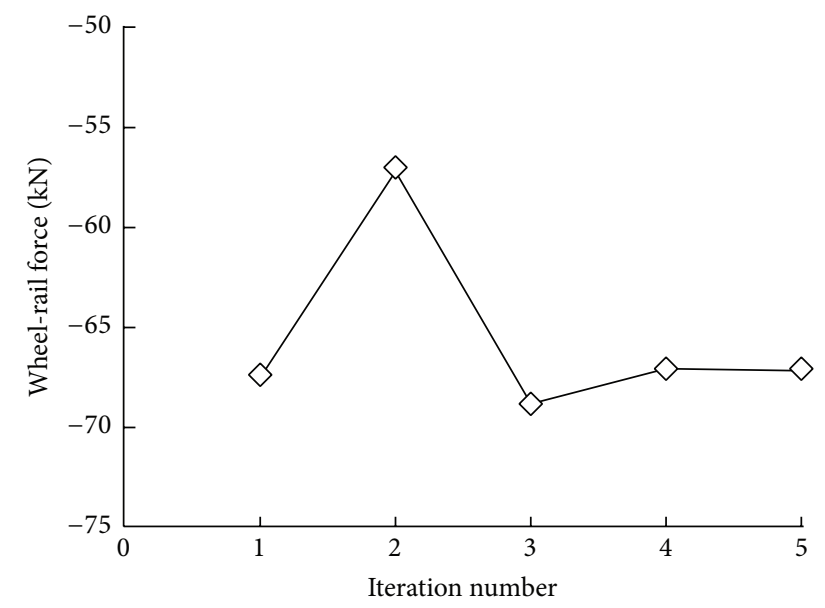

FIGURE 6: Iteration process for the wheel-rail contact force at time $t$.

Figures 10 and 11 are the time history of the wheel-to-rail contact forces with the linear and nonlinear contact model for different train speeds, respectively, where the values of the wheel-to-rail contact forces with the linear and the nonlinear contact model without irregularity excitation are shown in Table 16.

It is indicated that the train speed has a great influence on the displacements of the slab track structure, shown in Tables 3-5 and Figures $8(a)-8(c)$. With the increase of the train

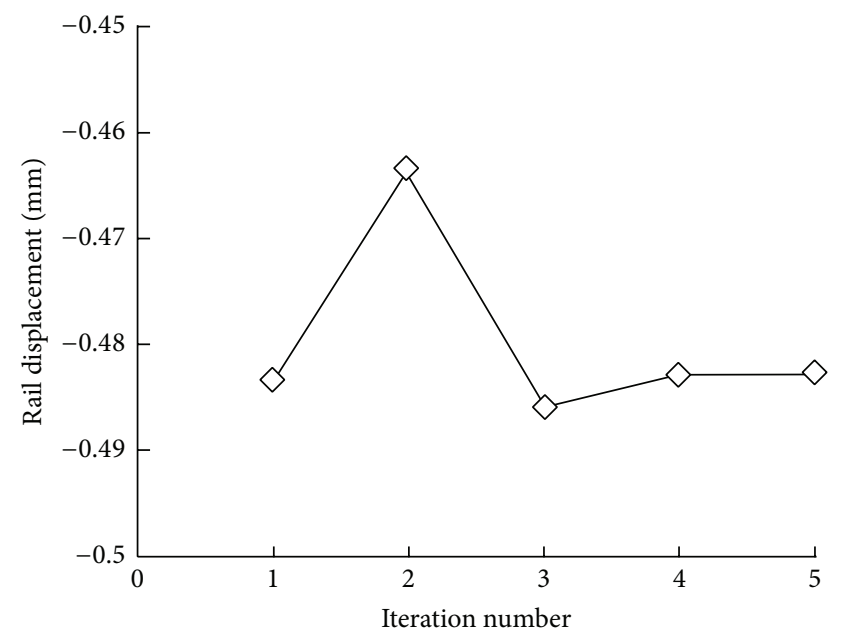

FIGURE 7: Iteration process for the rail displacement of wheel-rail contact point at time $t$.

speed from $200 \mathrm{~km} / \mathrm{h}$ to $350 \mathrm{~km} / \mathrm{h}$, the total amplitudes of displacement for rail, concrete slab, and hydraulically bonded layer in case of the wheel-to-rail linear contact model increase from $1.55 \mathrm{~mm}, 0.83 \mathrm{~mm}$, and $0.8 \mathrm{~mm}$ to $2.18 \mathrm{~mm}, 1.24 \mathrm{~mm}$, and $1.23 \mathrm{~mm}$, respectively, and the increased amplitude ratios are $40.3 \%, 49 \%$, and $53 \%$, respectively. For the wheel-to-rail nonlinear contact model, the increased amplitude ratios are $35.7 \%$, $46.8 \%$, and $45.5 \%$. 
TABLE 4: The maximum and the total amplitude of the concrete slab displacements.

\begin{tabular}{lcccccc}
\hline \multirow{2}{*}{ Speed $(\mathrm{km} / \mathrm{h})$} & \multicolumn{3}{c}{ Wheel-to-rail linear contact } & \multicolumn{3}{c}{ Wheel-to-rail nonlinear contact } \\
& Max $(\mathrm{mm})$ & Min $(\mathrm{mm})$ & Total amplitude $(\mathrm{mm})$ & Max $(\mathrm{mm})$ & Min $(\mathrm{mm})$ & Total amplitude (mm) \\
\hline 350 & 0.24 & -1.00 & 1.24 & 0.28 & -0.95 & 1.23 \\
300 & 0.22 & -0.95 & 1.17 & 0.26 & -0.83 & 1.09 \\
250 & 0.19 & -0.77 & 0.96 & 0.18 & -0.73 & 0.92 \\
200 & 0.14 & -0.70 & 0.83 & 0.15 & -0.69 & 0.84 \\
\hline
\end{tabular}

TABLE 5: The maximum and the total amplitude of the hydraulically bonded layer displacements.

\begin{tabular}{lcccccc}
\hline \multirow{2}{*}{ Speed $(\mathrm{km} / \mathrm{h})$} & \multicolumn{3}{c}{ Wheel-to-rail linear contact } & \multicolumn{3}{c}{ Wheel-to-rail nonlinear contact } \\
& Max $(\mathrm{mm})$ & Min $(\mathrm{mm})$ & Total amplitude $(\mathrm{mm})$ & Max $(\mathrm{mm})$ & Min $(\mathrm{mm})$ & Total amplitude (mm) \\
\hline 350 & 0.23 & -1.00 & 1.23 & 0.27 & -0.89 & 1.16 \\
300 & 0.21 & -0.89 & 1.11 & 0.25 & -0.80 & 1.05 \\
250 & 0.18 & -0.74 & 0.92 & 0.18 & -0.69 & 0.86 \\
200 & 0.13 & -0.67 & 0.80 & 0.14 & -0.65 & 0.79 \\
\hline
\end{tabular}

TABLE 6: The maximum and the total amplitude of the rail accelerations.

\begin{tabular}{lcccccc}
\hline \multirow{2}{*}{ Speed $(\mathrm{km} / \mathrm{h})$} & \multicolumn{3}{c}{ Wheel-to-rail linear contact } & \multicolumn{3}{c}{ Wheel-to-rail nonlinear contact } \\
& Max $\left(\mathrm{m} / \mathrm{s}^{2}\right)$ & Min $\left(\mathrm{m} / \mathrm{s}^{2}\right)$ & Total amplitude $\left(\mathrm{m} / \mathrm{s}^{2}\right)$ & Max $\left(\mathrm{m} / \mathrm{s}^{2}\right)$ & Min $\left(\mathrm{m} / \mathrm{s}^{2}\right)$ & Total amplitude $\left(\mathrm{m} / \mathrm{s}^{2}\right)$ \\
\hline 350 & 1216.60 & -1182.80 & 2399.40 & 664.90 & -663.08 & 1327.98 \\
300 & 897.09 & -633.52 & 1530.61 & 267.08 & -392.29 & 659.37 \\
250 & 337.01 & -408.99 & 746.00 & 285.72 & -288.94 & 574.66 \\
200 & 240.05 & -186.72 & 426.76 & 206.82 & -203.03 & 409.86 \\
\hline
\end{tabular}

TABLE 7: The maximum and the total amplitude of the concrete slab accelerations.

\begin{tabular}{lcccccc}
\hline \multirow{2}{*}{ Speed $(\mathrm{km} / \mathrm{h})$} & \multicolumn{3}{c}{ Wheel-to-rail linear contact } & \multicolumn{3}{c}{ Wheel-to-rail nonlinear contact } \\
& Max $\left(\mathrm{m} / \mathrm{s}^{2}\right)$ & Min $\left(\mathrm{m} / \mathrm{s}^{2}\right)$ & Total amplitude $\left(\mathrm{m} / \mathrm{s}^{2}\right)$ & Max $\left(\mathrm{m} / \mathrm{s}^{2}\right)$ & Min $\left(\mathrm{m} / \mathrm{s}^{2}\right)$ & Total amplitude $\left(\mathrm{m} / \mathrm{s}^{2}\right)$ \\
\hline 350 & 40.83 & -41.48 & 82.32 & 36.59 & -43.31 & 79.90 \\
300 & 29.89 & -45.18 & 75.07 & 38.79 & -35.72 & 74.51 \\
250 & 26.21 & -27.71 & 53.92 & 28.82 & -24.99 & 53.81 \\
200 & 21.98 & -22.58 & 44.56 & 23.31 & -21.04 & 44.35 \\
\hline
\end{tabular}

TABLE 8: The maximum and the total amplitude of the hydraulically bonded layer accelerations.

\begin{tabular}{lcccccc}
\hline \multirow{2}{*}{ Speed $(\mathrm{km} / \mathrm{h})$} & \multicolumn{3}{c}{ Wheel-to-rail linear contact } & \multicolumn{3}{c}{ Wheel-to-rail nonlinear contact } \\
& Max $\left(\mathrm{m} / \mathrm{s}^{2}\right)$ & Min $\left(\mathrm{m} / \mathrm{s}^{2}\right)$ & Total amplitude $\left(\mathrm{m} / \mathrm{s}^{2}\right)$ & Max $\left(\mathrm{m} / \mathrm{s}^{2}\right)$ & Min $\left(\mathrm{m} / \mathrm{s}^{2}\right)$ & Total amplitude $\left(\mathrm{m} / \mathrm{s}^{2}\right)$ \\
\hline 350 & 37.07 & -35.90 & 72.96 & 38.75 & -34.27 & 73.03 \\
300 & 29.17 & -33.71 & 62.87 & 34.62 & -27.94 & 62.56 \\
250 & 28.56 & -29.41 & 57.97 & 29.27 & -28.05 & 57.32 \\
200 & 21.92 & -22.64 & 44.56 & 22.99 & -21.45 & 44.43 \\
\hline
\end{tabular}

TABLE 9: The maximum and the total amplitude of the car body displacements.

\begin{tabular}{lcccccc}
\hline \multirow{2}{*}{ Speed $(\mathrm{km} / \mathrm{h})$} & \multicolumn{3}{c}{ Wheel-to-rail linear contact } & \multicolumn{3}{c}{ Wheel-to-rail nonlinear contact } \\
& Max $(\mathrm{mm})$ & Min $(\mathrm{mm})$ & Total amplitude $(\mathrm{mm})$ & Max $(\mathrm{mm})$ & Min $(\mathrm{mm})$ & Total amplitude $(\mathrm{mm})$ \\
\hline 350 & -0.2991 & -0.3013 & 0.0022 & -0.2989 & -0.3014 & 0.0025 \\
300 & -0.3001 & -0.3011 & 0.0010 & -0.3001 & -0.3013 & 0.0012 \\
250 & -0.3000 & -0.3011 & 0.0011 & -0.3001 & -0.3012 & 0.0011 \\
200 & -0.2998 & -0.3013 & 0.0015 & -0.2998 & -0.3014 & 0.0016 \\
\hline
\end{tabular}


TABLE 10: The maximum and the total amplitude of the bogie displacements.

\begin{tabular}{lcccccc}
\hline \multirow{2}{*}{ Speed $(\mathrm{km} / \mathrm{h})$} & \multicolumn{3}{c}{ Wheel-to-rail linear contact } & \multicolumn{3}{c}{ Wheel-to-rail nonlinear contact } \\
& Max $(\mathrm{mm})$ & Min $(\mathrm{mm})$ & Total amplitude $(\mathrm{mm})$ & Max $(\mathrm{mm})$ & Min $(\mathrm{mm})$ & Total amplitude $(\mathrm{mm})$ \\
\hline 350 & -0.0513 & -0.0617 & 0.0104 & -0.0497 & -0.0599 & 0.0102 \\
300 & -0.0515 & -0.0621 & 0.0106 & -0.0491 & -0.0598 & 0.0107 \\
250 & -0.0515 & -0.0625 & 0.0110 & -0.0487 & -0.0596 & 0.0109 \\
200 & -0.0515 & -0.0628 & 0.0113 & -0.0484 & -0.0597 & 0.0113 \\
\hline
\end{tabular}

TABLE 11: The maximum and the total amplitude of the wheel displacements.

\begin{tabular}{lcccccc}
\hline \multirow{2}{*}{ Speed $(\mathrm{km} / \mathrm{h})$} & \multicolumn{3}{c}{ Wheel-to-rail linear contact } & \multicolumn{3}{c}{ Wheel-to-rail nonlinear contact } \\
& Max $(\mathrm{mm})$ & Min $(\mathrm{mm})$ & Total amplitude $(\mathrm{mm})$ & Max $(\mathrm{mm})$ & Min $(\mathrm{mm})$ & Total amplitude $(\mathrm{mm})$ \\
\hline 350 & 0.0043 & -0.0088 & 0.0131 & 0.0070 & -0.0061 & 0.0131 \\
300 & 0.0042 & -0.0088 & 0.0130 & 0.0069 & -0.0061 & 0.0130 \\
250 & 0.0044 & -0.0087 & 0.0131 & 0.0068 & -0.0062 & 0.0130 \\
200 & 0.0043 & -0.0087 & 0.0130 & 0.0068 & -0.0061 & 0.0129 \\
\hline
\end{tabular}

TABLE 12: The maximum and the total amplitude of the car body accelerations.

\begin{tabular}{lcccccc}
\hline \multirow{2}{*}{ Speed $(\mathrm{km} / \mathrm{h})$} & \multicolumn{3}{c}{ Wheel-to-rail linear contact } & \multicolumn{3}{c}{ Wheel-to-rail nonlinear contact } \\
& Max $\left(\mathrm{m} / \mathrm{s}^{2}\right)$ & Min $\left(\mathrm{m} / \mathrm{s}^{2}\right)$ & Total amplitude $\left(\mathrm{m} / \mathrm{s}^{2}\right)$ & Max $\left(\mathrm{m} / \mathrm{s}^{2}\right)$ & $\mathrm{Min}\left(\mathrm{m} / \mathrm{s}^{2}\right)$ & Total amplitude $\left(\mathrm{m} / \mathrm{s}^{2}\right)$ \\
\hline 350 & 0.5371 & -0.5987 & 1.1358 & 0.6405 & -0.5037 & 1.1442 \\
300 & 0.4673 & -0.5702 & 1.0375 & 0.5587 & -0.4787 & 1.0374 \\
250 & 0.4510 & -0.5025 & 0.9535 & 0.5058 & -0.4491 & 0.9549 \\
200 & 0.3920 & -0.4476 & 0.8396 & 0.4478 & -0.3924 & 0.8402 \\
\hline
\end{tabular}

TABLE 13: The maximum and the total amplitude of the bogie accelerations.

\begin{tabular}{lcccccc}
\hline \multirow{2}{*}{ Speed $(\mathrm{km} / \mathrm{h})$} & \multicolumn{3}{c}{ Wheel-to-rail linear contact } & \multicolumn{3}{c}{ Wheel-to-rail nonlinear contact } \\
& Max $\left(\mathrm{m} / \mathrm{s}^{2}\right)$ & Min $\left(\mathrm{m} / \mathrm{s}^{2}\right)$ & Total amplitude $\left(\mathrm{m} / \mathrm{s}^{2}\right)$ & Max $\left(\mathrm{m} / \mathrm{s}^{2}\right)$ & Min $\left(\mathrm{m} / \mathrm{s}^{2}\right)$ & Total amplitude $\left(\mathrm{m} / \mathrm{s}^{2}\right)$ \\
\hline 350 & 8.7542 & -10.2306 & 18.9848 & 10.3481 & -8.7413 & 19.0894 \\
300 & 8.2912 & -10.498 & 18.7892 & 10.5706 & -8.286 & 18.8566 \\
250 & 7.5458 & -10.4057 & 17.9515 & 10.4155 & -7.5164 & 17.9319 \\
200 & 7.7872 & -11.4046 & 19.1918 & 11.5383 & -7.8205 & 19.3588 \\
\hline
\end{tabular}

TABLE 14: The maximum and the total amplitude of the wheel accelerations.

\begin{tabular}{lcccccc}
\hline \multirow{2}{*}{ Speed $(\mathrm{km} / \mathrm{h})$} & \multicolumn{3}{c}{ Wheel-to-rail linear contact } & \multicolumn{3}{c}{ Wheel-to-rail nonlinear contact } \\
& Max $\left(\mathrm{m} / \mathrm{s}^{2}\right)$ & Min $\left(\mathrm{m} / \mathrm{s}^{2}\right)$ & Total amplitude $\left(\mathrm{m} / \mathrm{s}^{2}\right)$ & Max $\left(\mathrm{m} / \mathrm{s}^{2}\right)$ & Min $\left(\mathrm{m} / \mathrm{s}^{2}\right)$ & Total amplitude $\left(\mathrm{m} / \mathrm{s}^{2}\right)$ \\
\hline 350 & 77.82 & -60.49 & 138.30 & 74.52 & -57.27 & 131.79 \\
300 & 56.25 & -57.80 & 114.04 & 63.67 & -55.06 & 118.72 \\
250 & 54.17 & -52.96 & 107.13 & 55.12 & -50.77 & 105.89 \\
200 & 41.00 & -45.89 & 86.89 & 46.64 & -40.40 & 87.04 \\
\hline
\end{tabular}

The calculated maximum and the total amplitude of displacements for the rail, concrete slab, and hydraulically bonded layer with the linear contact model are larger than those with the nonlinear contact model, and the increasing range is within $10 \%$.

The maximum and the total amplitudes of accelerations for the rail, concrete slab, and hydraulically bonded layer increase with the increase of the train speeds, as shown in
Tables 6-8 and Figures $8(\mathrm{~d})-8(\mathrm{f})$. With the increase of the train speed from $200 \mathrm{~km} / \mathrm{h}$ to $350 \mathrm{~km} / \mathrm{h}$, the total amplitudes of the rail, concrete slab, and hydraulically bonded layer acceleration in case of the wheel-to-rail linear contact model increase from $426.76 \mathrm{~m} / \mathrm{s}^{2}, 44.56 \mathrm{~m} / \mathrm{s}^{2}$, and $44.56 \mathrm{~m} / \mathrm{s}^{2}$ to $2399.4 \mathrm{~m} / \mathrm{s}^{2}, 82.32 \mathrm{~m} / \mathrm{s}^{2}$, and $72.9 \mathrm{~m} / \mathrm{s}^{2}$ respectively, and the increased amplitude ratios are $462.2 \%, 84.7 \%$, and $38.9 \%$; for the wheel-to-rail nonlinear contact model, the increased 


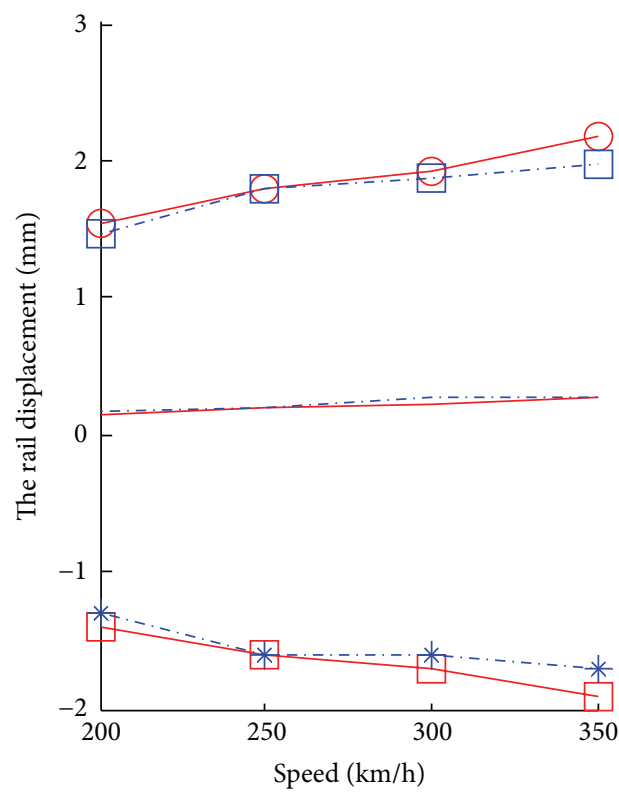

_ The maximum value in wheel-to-rail linear contact

$\square$ The minimum value in wheel-to-rail linear contact

$\checkmark$ The total amplitude in wheel-to-rail linear contact

... The maximum value in wheel-to-rail nonlinear contact

*- The minimum value in wheel-to-rail nonlinear contact

$\succeq-$ The total amplitude in wheel-to-rail nonlinear contact

(a)

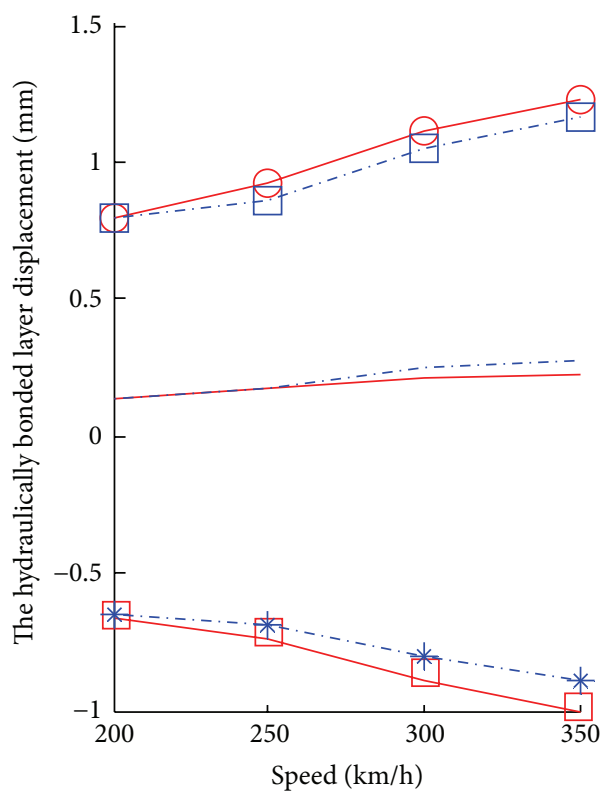

_ The maximum value in wheel-to-rail linear contact

$\square$ The minimum value in wheel-to-rail linear contact

- The total amplitude in wheel-to-rail linear contact

. . - The maximum value in wheel-to-rail nonlinear contact

*- The minimum value in wheel-to-rail nonlinear contact

$€-$ The total amplitude in wheel-to-rail nonlinear contact

(c)

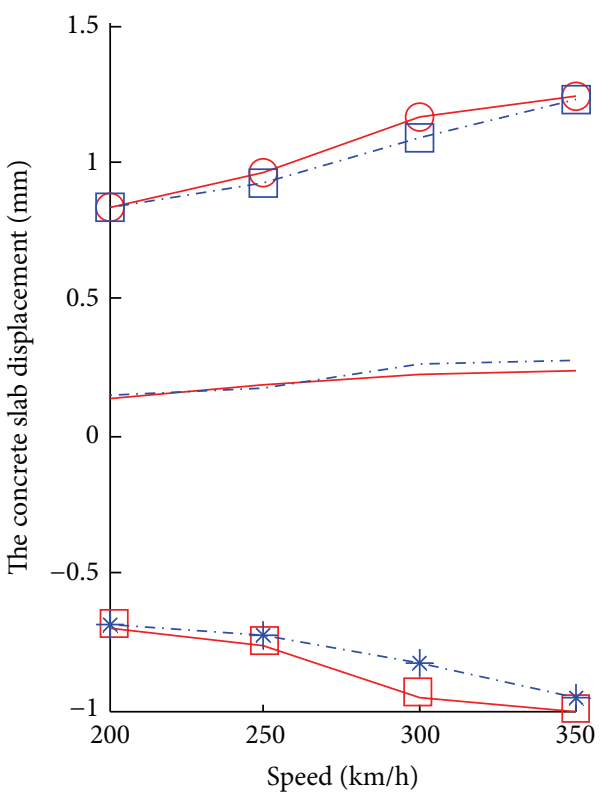

- The maximum value in wheel-to-rail linear contact

$\square$ The minimum value in wheel-to-rail linear contact

- The total amplitude in wheel-to-rail linear contact

... The maximum value in wheel-to-rail nonlinear contact

*- The minimum value in wheel-to-rail nonlinear contact

• - The total amplitude in wheel-to-rail nonlinear contact

(b)

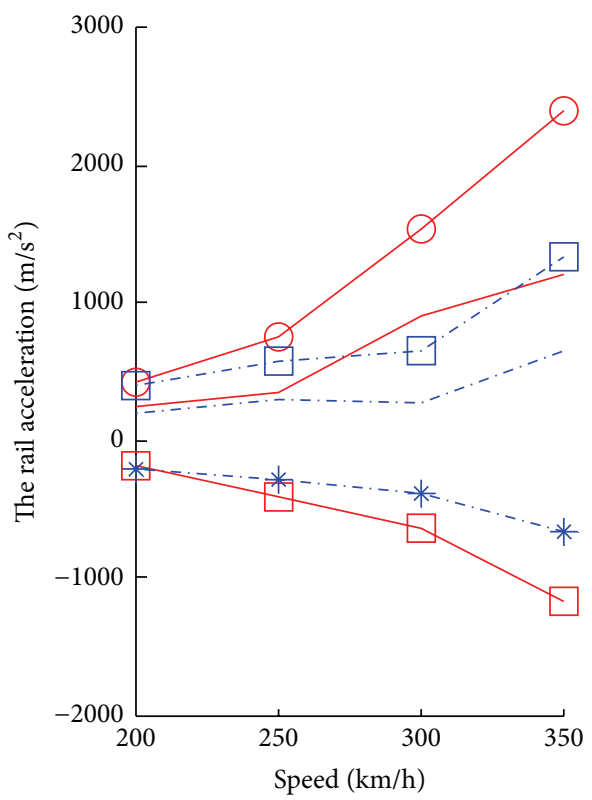

_ The maximum value in wheel-to-rail linear contact

$\square$ The minimum value in wheel-to-rail linear contact

- The total amplitude in wheel-to-rail linear contact

. - - The maximum value in wheel-to-rail nonlinear contact

*- The minimum value in wheel-to-rail nonlinear contact

$€-$ The total amplitude in wheel-to-rail nonlinear contact

FIgure 8: Continued. 


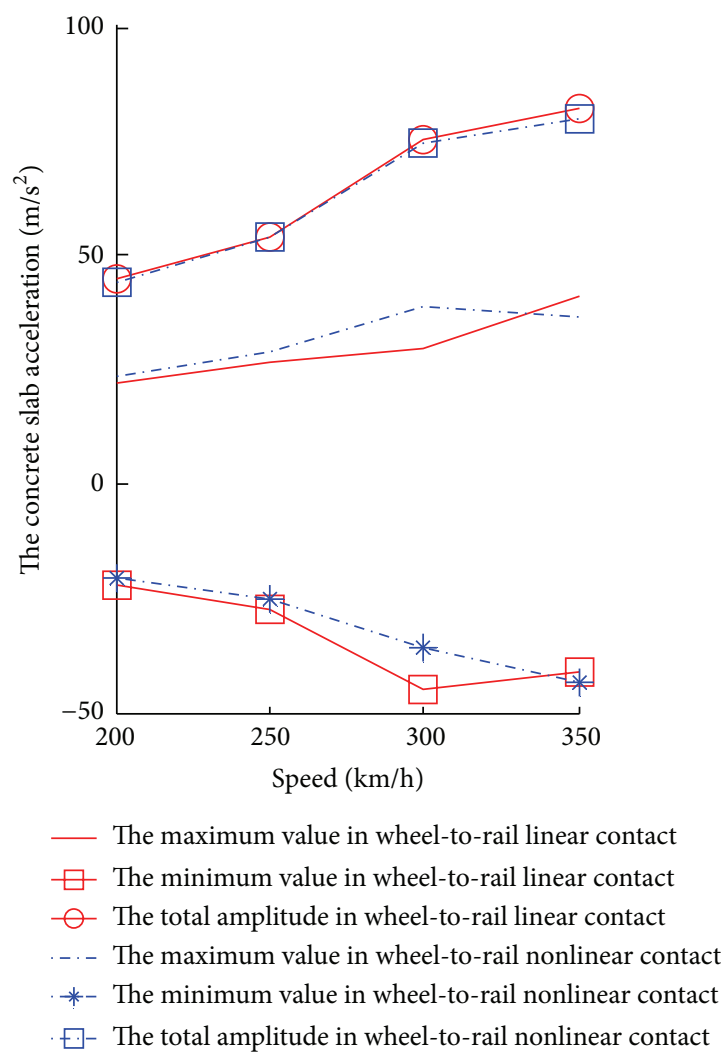

(e)

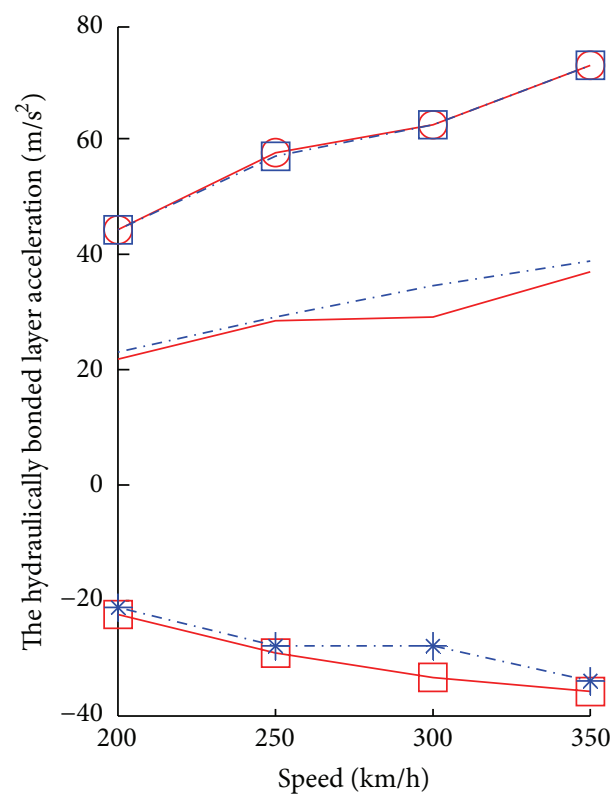

_ The maximum value in wheel-to-rail linear contact

$\square$ The minimum value in wheel-to-rail linear contact

- The total amplitude in wheel-to-rail linear contact

. -. - The maximum value in wheel-to-rail nonlinear contact

*- The minimum value in wheel-to-rail nonlinear contact

$€$ - The total amplitude in wheel-to-rail nonlinear contact

(f)

FIGURE 8: Dynamic response of the ballastless slab track subsystem: (a) the rail displacements, (b) the concrete slab displacements, (c) the hydraulically bonded layer displacements, (d) the rail accelerations, (e) the concrete slab accelerations, and (f) the hydraulically bonded layer accelerations.

TABLE 15: The maximum wheel-to-rail contact forces.

\begin{tabular}{lcc}
\hline Speed $(\mathrm{km} / \mathrm{h})$ & $\begin{array}{c}\text { Wheel-to-rail } \\
\text { linear contact }(\mathrm{kN})\end{array}$ & $\begin{array}{c}\text { Wheel-to-rail } \\
\text { nonlinear contact }(\mathrm{kN})\end{array}$ \\
\hline 350 & 172.38 & 166.31 \\
300 & 160.05 & 152.16 \\
250 & 142.41 & 141.95 \\
200 & 122.53 & 125.80 \\
\hline
\end{tabular}

TABLE 16: The maximum wheel-to-rail contact forces without irregularities excitation.

\begin{tabular}{lcc}
\hline Speed $(\mathrm{km} / \mathrm{h})$ & $\begin{array}{c}\text { Wheel-to-rail } \\
\text { linear contact }(\mathrm{kN})\end{array}$ & $\begin{array}{c}\text { Wheel-to-rail } \\
\text { nonlinear contact }(\mathrm{kN})\end{array}$ \\
\hline 350 & 69.58 & 69.54 \\
300 & 69.68 & 69.63 \\
250 & 69.82 & 69.79 \\
200 & 70.17 & 70.09 \\
\hline
\end{tabular}

amplitude ratios are $224 \%, 80.2 \%$, and $39.2 \%$. The higher the train speed, the more significant the difference of the rail acceleration.

The calculated total amplitudes of the rail acceleration with the wheel-to-rail linear contact model are larger than those with the wheel-to-rail nonlinear contact model. The higher the train speed is, the more obvious the difference will be, whereas the differences of the total amplitude for the concrete slab and the hydraulically bonded layer acceleration with both contact models are within $5 \%$.

As indicated in Tables 9-11 and Figures 9(a)-9(c), the maximum displacements of the car body, the bogie, and the wheel vary little with the train speed.

The calculated maximum absolute values of displacements for the bogie and the wheel with the wheel-to-rail linear contact model are larger than those with the nonlinear contact model, the increased ranges being within 5\% and $25 \%$, respectively. However, the maximum absolute value of displacement for the car body with the wheel-to-rail linear contact model is nearly equal to that with the nonlinear contact model at the same train speed.

As indicated in Tables 12-14 and Figures 9(d)-9(f), the maximum and total amplitudes of acceleration for the car body, the bogie, and the wheel increase with the increase of train speed from $200 \mathrm{~km} / \mathrm{h}$ to $350 \mathrm{~km} / \mathrm{h}$. Yet the maximum and the total amplitudes of the bogie acceleration at a speed of $200 \mathrm{~km} / \mathrm{h}$ are larger than those at a speed of $250 \mathrm{~km} / \mathrm{h}$. The cause may be track irregularity of an individual point being too large. The total amplitudes of acceleration for the car body, the bogie, and the wheel with the wheel-to-rail linear 


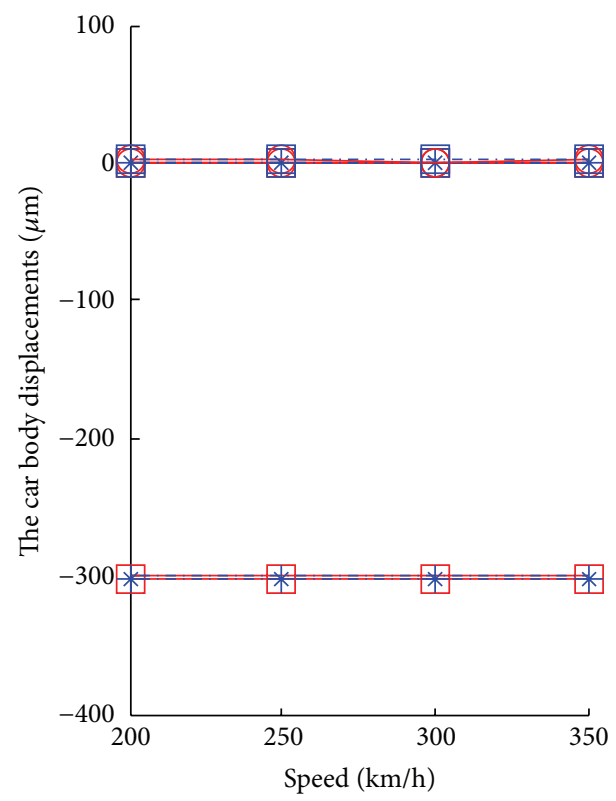

- The maximum value in wheel-to-rail linear contact

$\square$ The minimum value in wheel-to-rail linear contact

$\checkmark$ The total amplitude in wheel-to-rail linear contact

... The maximum value in wheel-to-rail nonlinear contact

*- The minimum value in wheel-to-rail nonlinear contact

.. The total amplitude in wheel-to-rail nonlinear contact

(a)

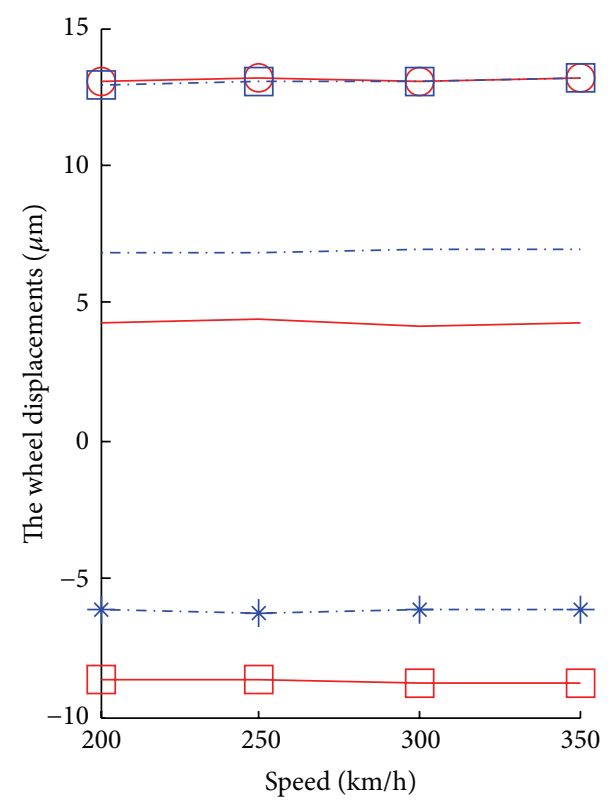

- The maximum value in wheel-to-rail linear contact

$\square$ The minimum value in wheel-to-rail linear contact

$\checkmark$ The total amplitude in wheel-to-rail linear contact

...- The maximum value in wheel-to-rail nonlinear contact

*- The minimum value in wheel-to-rail nonlinear contact

๑- The total amplitude in wheel-to-rail nonlinear contact

(c)

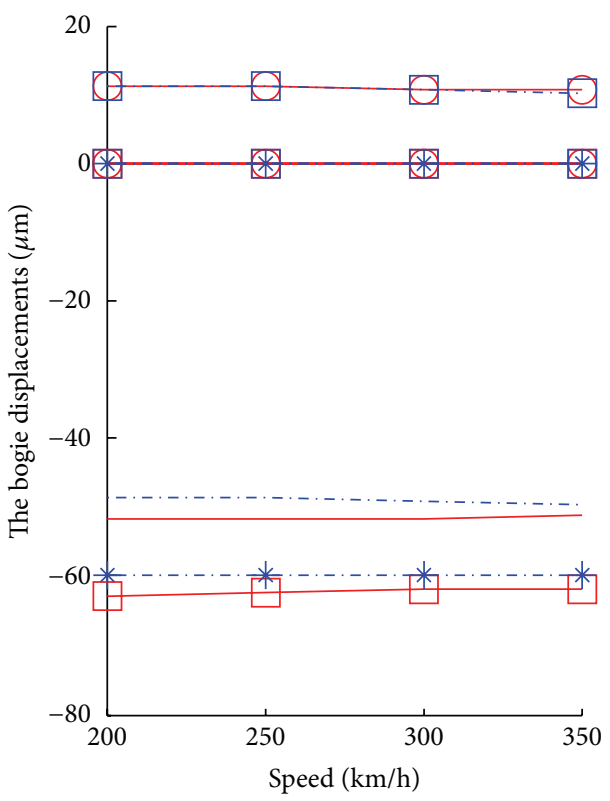

- The maximum value in wheel-to-rail linear contact

$\square$ The minimum value in wheel-to-rail linear contact

$\checkmark$ The total amplitude in wheel-to-rail linear contact

... The maximum value in wheel-to-rail nonlinear contact

*- The minimum value in wheel-to-rail nonlinear contact

-. The total amplitude in wheel-to-rail nonlinear contact

(b)

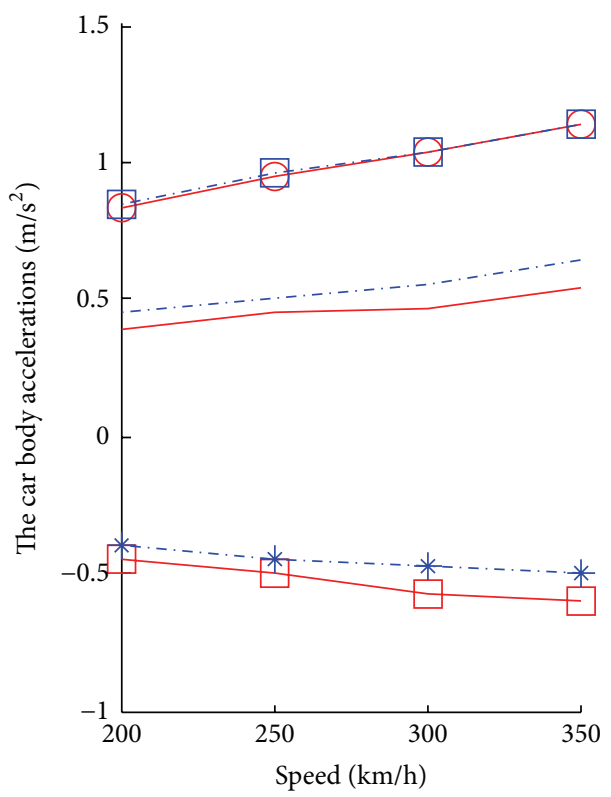

_ The maximum value in wheel-to-rail linear contact

$\square$ The minimum value in wheel-to-rail linear contact

$\checkmark$ The total amplitude in wheel-to-rail linear contact

. - . - The maximum value in wheel-to-rail nonlinear contact

*- The minimum value in wheel-to-rail nonlinear contact

• - The total amplitude in wheel-to-rail nonlinear contact

Figure 9: Continued. 


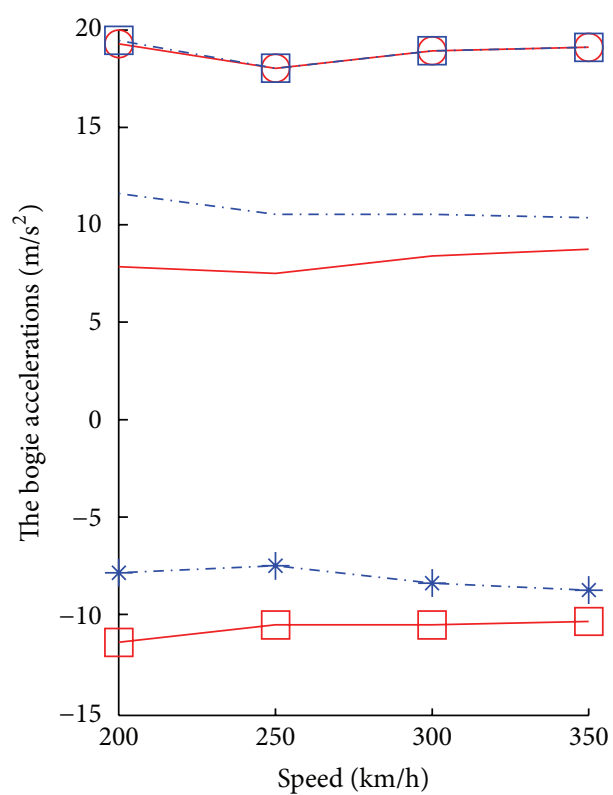

_ The maximum value in wheel-to-rail linear contact

$\square$ The minimum value in wheel-to-rail linear contact

$\checkmark$ The total amplitude in wheel-to-rail linear contact

... - The maximum value in wheel-to-rail nonlinear contact

*- The minimum value in wheel-to-rail nonlinear contact

๑- The total amplitude in wheel-to-rail nonlinear contact

(e)

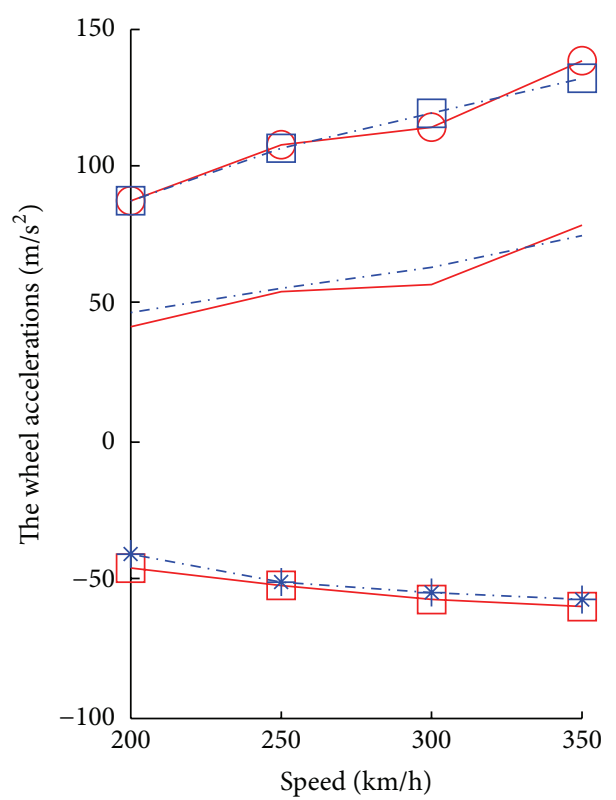

_ The maximum value in wheel-to-rail linear contact

$\square$ The minimum value in wheel-to-rail linear contact

$\checkmark$ The total amplitude in wheel-to-rail linear contact

. - - The maximum value in wheel-to-rail nonlinear contact

*- The minimum value in wheel-to-rail nonlinear contact

$\succeq$ - The total amplitude in wheel-to-rail nonlinear contact

(f)

Figure 9: Dynamic response of the vehicle subsystem: (a) the car body displacements, (b) the bogie displacements, (c) the wheel displacements, (d) the car body accelerations, (e) the bogie accelerations, and (f) the wheel accelerations.

contact model are nearly equal to those with the nonlinear contact model, where the differences are within $5 \%$.

It is indicated that the train speed has a great influence on the wheel-to-rail contact forces, as shown in Figures 10 and 11 and Table 15. With the increase of the train speed from $200 \mathrm{~km} / \mathrm{h}$ to $350 \mathrm{~km} / \mathrm{h}$, the calculated maximum wheelrail contact force increases from $122.53 \mathrm{kN}$ to $172.38 \mathrm{kN}$ with the wheel-to-rail linear contact model, and the increased amplitude ratio is $40.68 \%$. For the wheel-to-rail nonlinear contact model, the calculated maximum wheel-rail contact force increases from $125.8 \mathrm{kN}$ to $166.31 \mathrm{kN}$, and the increased amplitude ratio is $32.2 \%$.

The maximum wheel-rail contact force with the linear contact model is slightly larger than that with the nonlinear contact model, where the increasing range is within $5 \%$. However, at a train speed of $200 \mathrm{~km} / \mathrm{h}$, the maximum wheelrail contact force with the linear contact model is slightly smaller than that with the nonlinear contact model.

\section{Conclusions}

A model for dynamic analysis of the vehicle-track nonlinear coupling system is established by finite element method. And a cross iteration algorithm is presented to solve the nonlinear dynamic equation of the vehicle-track coupling system. In simulation analysis, the whole system is divided into two subsystems, that is, the vehicle subsystem considered as a rolling stock unit with a primary and secondary suspension system and the track subsystem regarded as a three-elasticbeam model. Coupling of the two systems is achieved by equilibrium conditions for wheel-rail nonlinear contact forces and geometrical compatibility conditions. The test computation examples show that a relatively small time step must be selected to ensure convergence, which will greatly increase the computation time. In order to solve this problem and accelerate the iterative convergence rate, a relaxation technique is introduced to modify the wheel-rail contact force. Based on the dynamic analysis of the high speed train and slab track nonlinear coupling system, the following conclusions are obtained.

(1) The train speed has a significant influence on the dynamic responses of the train and the track structures. Regardless of the wheel-to-rail linear contact model or nonlinear contact model, the accelerations and the displacements of the rail, the concrete slab, and the hydraulically bonded layer (and the accelerations of the wheel, the bogie, and the car body), as well as the wheel-rail contact forces, increase with the increase of the train speeds, while the displacements of the wheel, the bogie, and the car body vary little with the train speed.

(2) Results of the dynamic responses for the train and the track structure with the wheel-to-rail linear contact model 


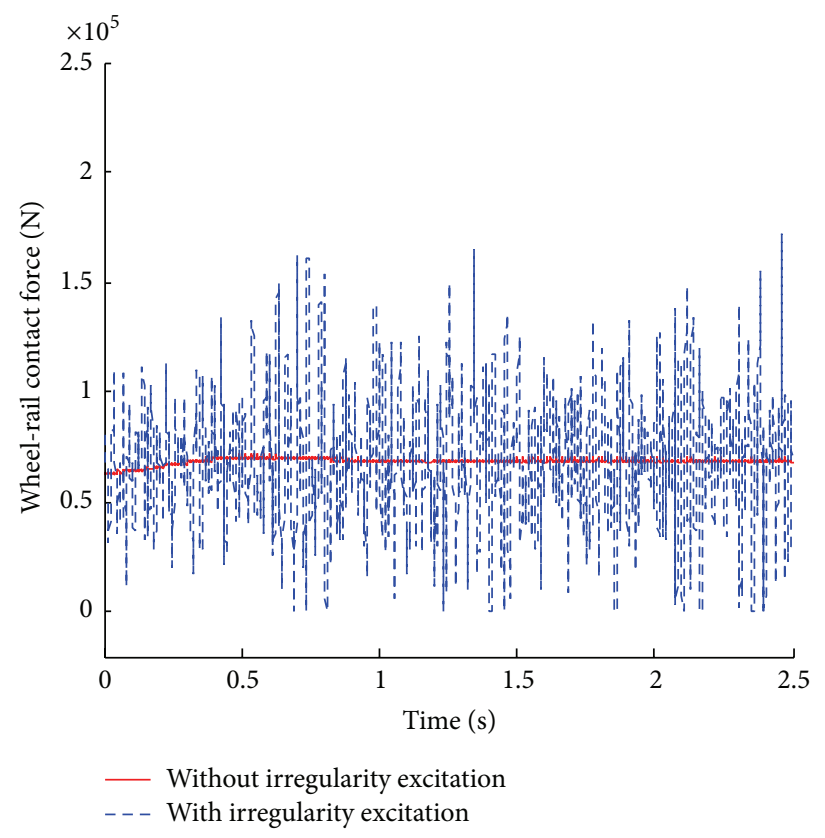

(a) At the speed of $350 \mathrm{~km} / \mathrm{h}$

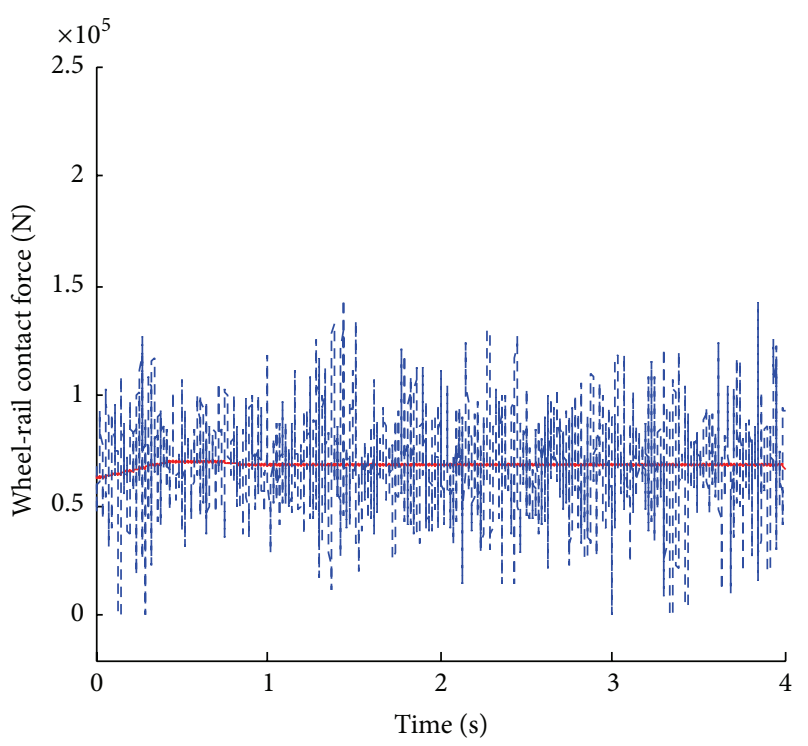

- Without irregularity excitation
-- With irregularity excitation

(c) At the speed of $250 \mathrm{~km} / \mathrm{h}$

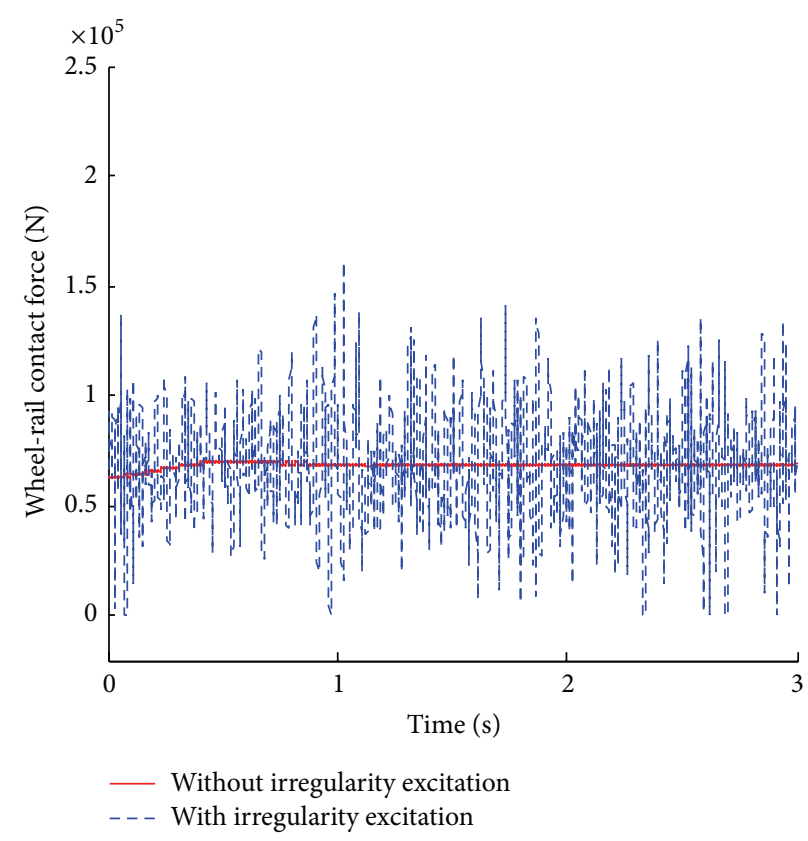

(b) At the speed of $300 \mathrm{~km} / \mathrm{h}$

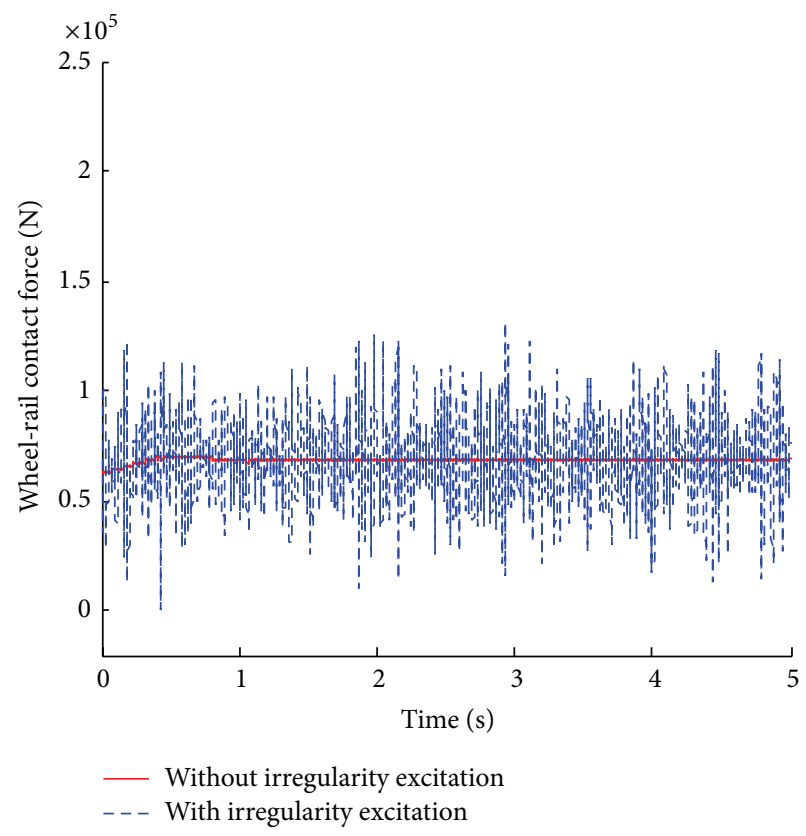

(d) At the speed of $200 \mathrm{~km} / \mathrm{h}$

FIGURE 10: Time history of the wheel-rail contact force with the linear contact model: (a) at the speed of $350 \mathrm{~km} / \mathrm{h}$, (b) at the speed of $300 \mathrm{~km} / \mathrm{h}$, (c) at the speed of $250 \mathrm{~km} / \mathrm{h}$, and (d) at the speed of $200 \mathrm{~km} / \mathrm{h}$.

are larger than those with the wheel-to-rail nonlinear contact model under the same train speed. The differences for the maximum and the total amplitudes of the displacements and the accelerations are in the range of $10 \%$, and the differences for the wheel-rail contact forces are within 5\%. Meanwhile, the train speed has a great influence on the difference for rail acceleration. The higher the train speed is, the larger the differences of the rail acceleration will be. The total amplitude of the rail acceleration with the wheel-to-rail linear contact model is twice as large as that with the wheel-to-rail nonlinear contact model at higher train speed, whereas the difference of the rail acceleration is within 5\% at lower train speed. Summarily, it is conservative and safer to make the design of the train and the track structure based on the computational results with the wheel-to-rail linear contact model.

(3) The introduction of the relaxation coefficient to modify the wheel-rail contact force can evidently accelerate the convergence speed of the cross iterative algorithm. 

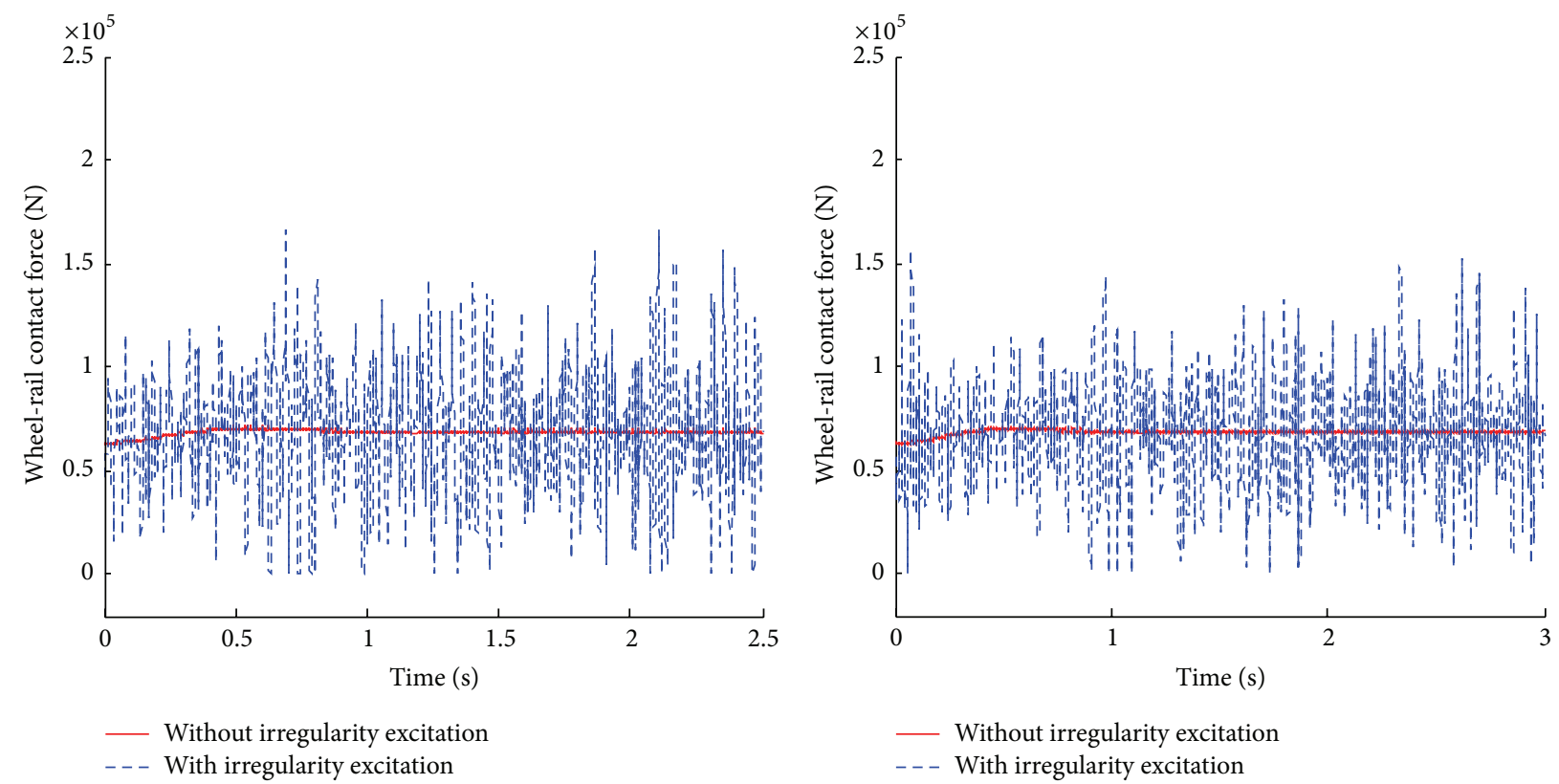

(a) At the speed of $350 \mathrm{~km} / \mathrm{h}$

(b) At the speed of $300 \mathrm{~km} / \mathrm{h}$
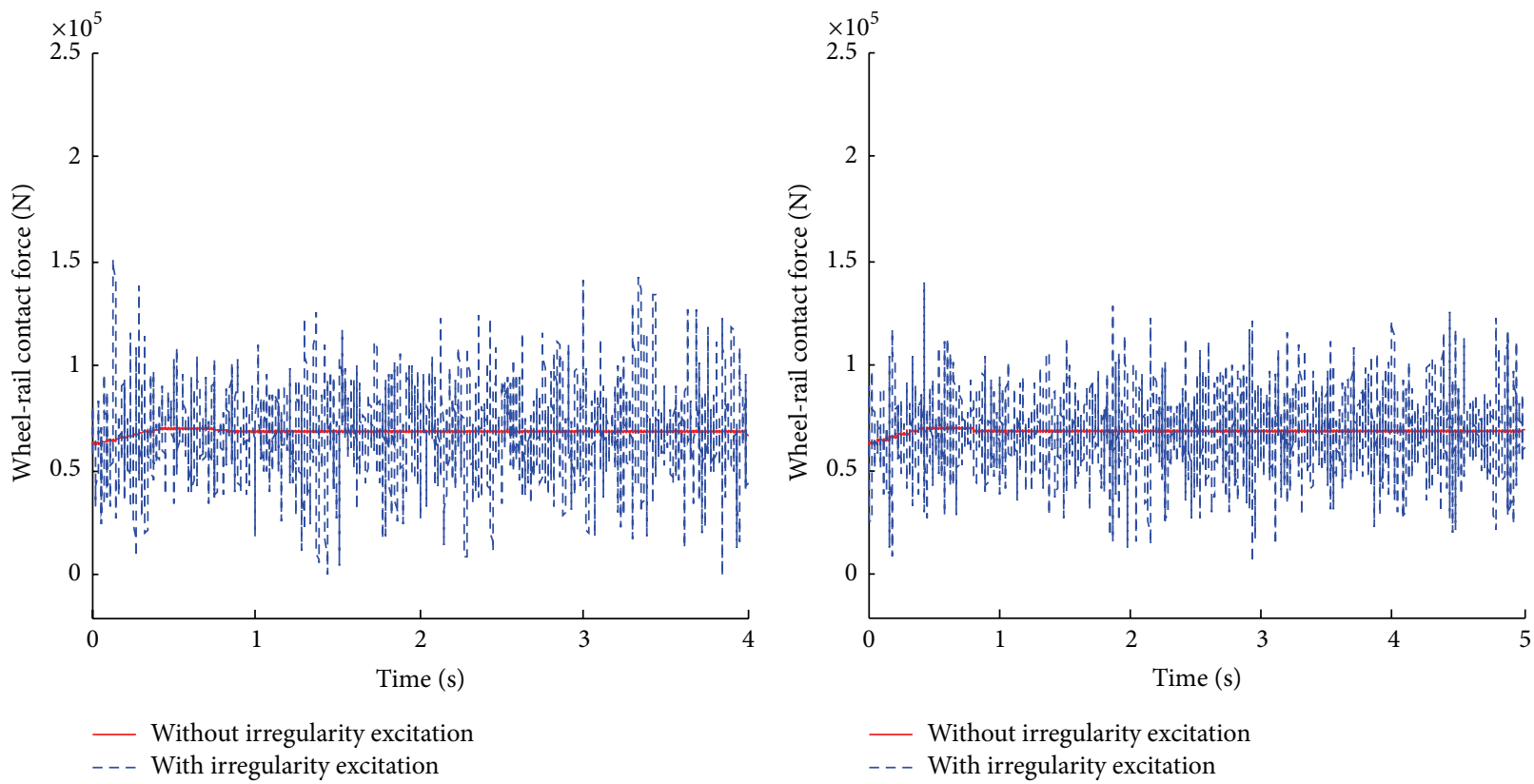

(c) At the speed of $250 \mathrm{~km} / \mathrm{h}$

(d) At the speed of $200 \mathrm{~km} / \mathrm{h}$

FIGURE 11: Time history of the wheel-rail contact force with the nonlinear contact model: (a) at the speed of $350 \mathrm{~km} / \mathrm{h}$, (b) at the speed of $300 \mathrm{~km} / \mathrm{h},(\mathrm{c})$ at the speed of $250 \mathrm{~km} / \mathrm{h}$, and (d) at the speed of $200 \mathrm{~km} / \mathrm{h}$.

The computation tests show that only 3 to 6 iteration steps are required to approach the convergence in each iteration.

(4) As the vehicle and slab track coupling nonlinear system is divided into the vehicle subsystem and the track subsystem, the dynamic equations of the two subsystems can be solved independently. This method can not only reduce the analysis scale of the problem, but also reduce the difficulty of the programming design. At the same time, the coefficient matrices of the finite element equation for the two subsystems are constant and symmetric, and inverting is only required once. In the computation procedure, the same inverted matrices can be substituted in each iteration and each time step. As a result, the computation speed is greatly enhanced. In contrast with the existing method of "set-in-right-position" to dynamic analysis of the vehicletrack coupling system, the coefficient matrices of the finite element equations change with the change of the position of the train on the track. Therefore, inversion calculation is 
necessary in every time step, which greatly reduces the computational efficiency. A conclusion, by simulating analysis of the dynamic responses for the vehicle and the slab track structure (which are induced by the train moving on the track with the length of $370 \mathrm{~m}$ ), is obtained: that the computing time in the ordinary computer workstation is of only 40minute duration with the cross iteration algorithm, compared with the 150 minutes required by the method of "set-inright-position" (details of the computers and programming languages and systems employed are as follows: (1) CPU: Intel(R) core(TM) i5-2400 CPU @ 3.1 GHz 3.1 GHz; (2) RAM: $4.00 \mathrm{~GB}$; (3) programming languages: MATLAB R2010b). The computation efficiency of the former method is 3 to 5 times higher than the latter under normal conditions. If the scale of the analyzed problem is larger, the computation efficiency will be higher.

It should be pointed out that the proposed algorithm has a general applicability, which can be used to analyze all kinds of the linear and the nonlinear problems under moving loads.

\section{Conflict of Interests}

The authors declare that there is no conflict of interests regarding the publication of this paper.

\section{Acknowledgments}

The work reported herein was supported by the Engineering Research Center of Railway Environment Vibration and Noise, the Ministry of Education, and the Natural Science Foundation of China (51478184).

\section{References}

[1] H. Huawu, "Ballastless track shall be developed in great efforts on Chinese passenger dedicated lines," Chinese Railways, no. 1 , pp. 11-15, 2005.

[2] W. H. Zhang, “The development of China's high-speed railway systems and a study of the dynamics of coupled systems in high-speed trains," Proceedings of the Institution of Mechanical Engineers, Part F: Journal of Rail and Rapid Transit, vol. 228, no. 4, pp. 367-377, 2014

[3] C. Esveld, "Recent developments in slab track," European Railway Review, vol. 9, pp. 81-86, 2003.

[4] J. M. Zwarthoed, V. L. Markine, and C. Esveld, "Slab track design: flexural stiffness versus soil improvement," in Proceedings of the Rail-Tech Europe Conference, CDR, Utrecht, The Netherlands, April 2001.

[5] W. Zhai, W. Han, C. Cai, and Q. Wang, "Dynamic properties of high-speed railway slab tracks," Journal of the China Railway Society, vol. 21, no. 6, pp. 65-69, 1999 (Chinese).

[6] J. Xiang, D. He, and Q.-Y. Zeng, "Analysis method of vertical vibration of train and ballastless track system with the lateral finite strip and slab segment element," Journal of the China Railway Society, vol. 29, no. 4, pp. 64-69, 2007 (Chinese).

[7] J. Xiang, D. He, and Q.-Y. Zeng, "Analysis theory of spatial vibration of high-speed train and slab track system," Journal of Central South University of Technology, vol. 15, no. 1, pp. 121-126, 2008.
[8] L. Dong, C. Zhao, D. Cai, Q. Zhang, and Y. Ye, "Experimental validation of a numerical model for prediction of the dynamic response of ballastless subgrade of high-speed railways," China Civil Engineering Journal, vol. 41, no. 10, pp. 81-86, 2008 (Chinese).

[9] X. Lei and B. Zhang, "Analysis of dynamic behavior for slab track of high-speed railway based on vehicle and track elements," Journal of Transportation Engineering, vol. 137, no. 4, pp. 227-240, 2011.

[10] X. Lei and J. Wang, "Dynamic analysis of the train and slab track coupling system with finite elements in a moving frame of reference," Journal of Vibration and Control, vol. 20, no. 9, pp. 1301-1317, 2014.

[11] X. Kang, X. Liu, H. Li, F. Yang, J. Gao, and W. Zhai, "PSD of ballastless track irregularities of high-speed railway," Scientia Sinica Technologica, vol. 44, no. 7, pp. 687-696, 2014.

[12] J. Zhang, Y. Zhao, Y.-H. Zhang et al., "Non-stationary random vibration of a coupled vehicle-slab track system using a parallel algorithm based on the pseudo excitation method," Proceedings of the Institution of Mechanical Engineers, Part F: Journal of Rail and Rapid Transit, vol. 227, no. 3, pp. 203-216, 2013.

[13] J. N. Varandas, P. Hölscher, and M. A. G. Silva, "Settlement of ballasted track under traffic loading: application to transition zones," Proceedings of the Institution of Mechanical Engineers, Part F: Journal of Rail and Rapid Transit, vol. 228, no. 3, pp. 242259, 2014.

[14] K. Nguyen, J. M. Goicolea, and F. Galbadón, “Comparison of dynamic effects of high-speed traffic load on ballasted track using a simplified two-dimensional and full three-dimensional model," Proceedings of the Institution of Mechanical Engineers, Part F: Journal of Rail and Rapid Transit, vol. 228, no. 2, pp. 128142, 2014

[15] F. Yang and G. A. Fonder, "An iterative solution method for dynamic response of bridge-vehicles systems," Earthquake Engineering and Structural Dynamics, vol. 25, no. 2, pp. 195-215, 1996.

[16] W. Zhai, H. Xia, C. Cai et al., "High-speed train-track-bridge dynamic interactions-part I: theoretical model and numerical simulation," International Journal of Rail Transportation, vol. 1, no. 1-2, pp. 3-24, 2013.

[17] W. Zhai, S. Wang, N. Zhang et al., "High-speed train-trackbridge dynamic interactions-part II: experimental validation and engineering application," International Journal of Rail Transportation, vol. 1, no. 1-2, pp. 25-41, 2013.

[18] S. G. M. Neves, A. F. M. Azevedo, and R. Calçada, "A direct method for analyzing the vertical vehicle-structure interaction," Engineering Structures, vol. 34, pp. 414-420, 2012.

[19] S. G. M. Neves, P. A. Montenegro, A. F. M. Azevedo, and R. Calçada, "A direct method for analyzing the non-linear vehiclestructure interaction," Engineering Structures, vol. 69, pp. 83-89, 2014.

[20] L. Xiaoyan, A. Khomenko, and A. Elena, "Innovation \& sustainability of modern railway," in Proceedings of the 3rd International Symposium on Innovation \& Sustainability of Modern Railway, L. Xiaoyan, Ed., Nanchang, China, September 2012.

[21] O. C. Zienkiewicz, The Finite Element Method, McGraw-Hill, New York, NY, USA, 1977. 


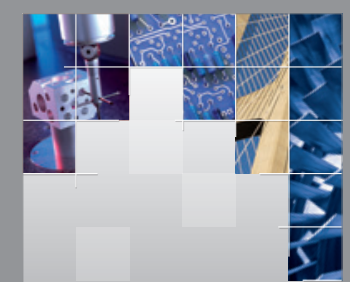

\section{Enfincering}
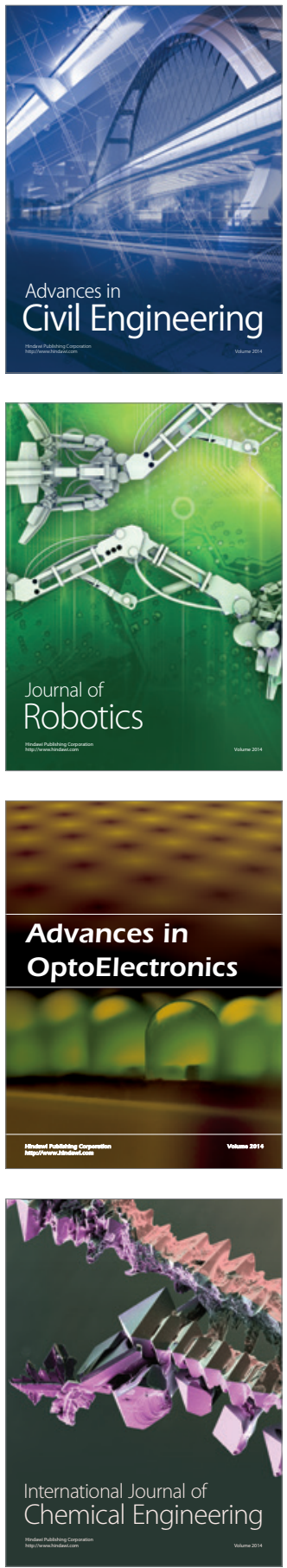

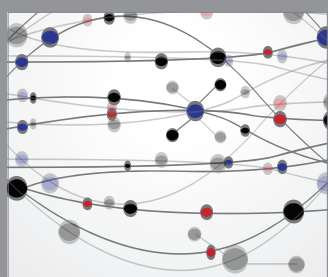

The Scientific World Journal

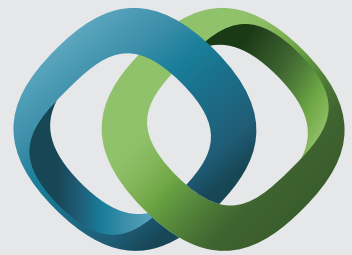

\section{Hindawi}

Submit your manuscripts at

http://www.hindawi.com
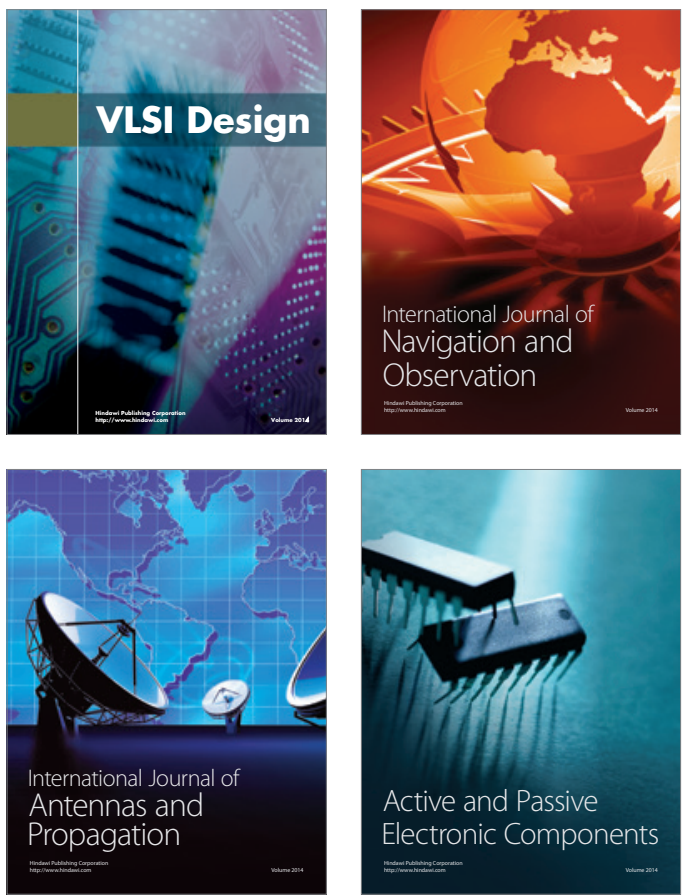
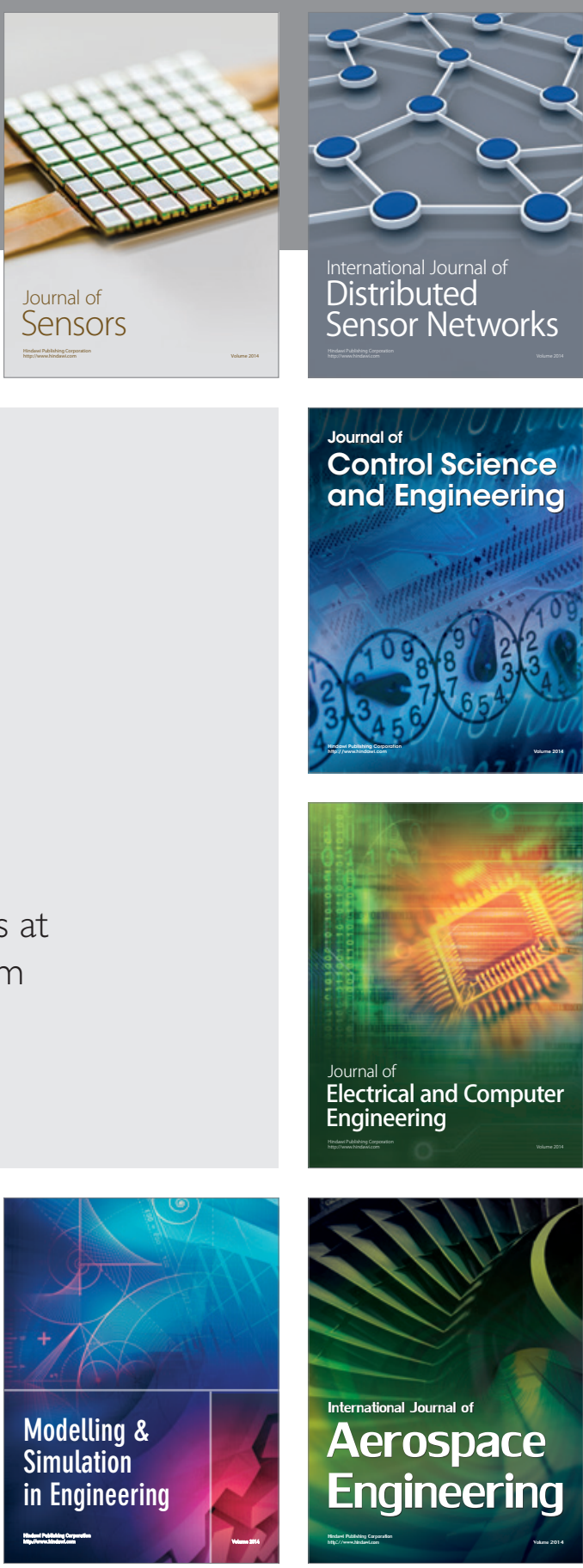

International Journal of

Distributed

Sensor Networks

Journal of

Control Science

and Engineering
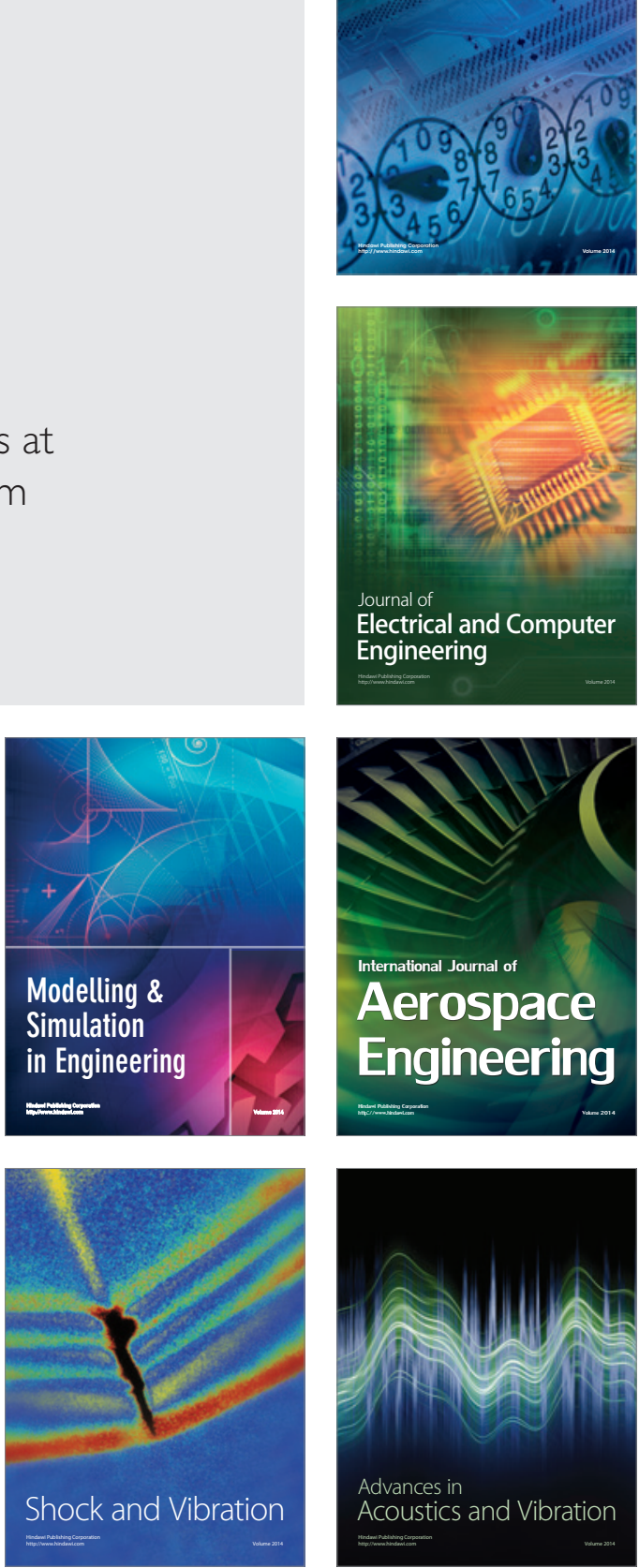